Georgia State University

ScholarWorks @ Georgia State University

Nutrition Theses

Department of Nutrition

Summer 8-8-2010

\title{
The Relationship between Within-Day Energy Balance and Menstruation in Active Females
}

Alexandra J. Friel

Georgia State University

Follow this and additional works at: https://scholarworks.gsu.edu/nutrition_theses

Part of the Nutrition Commons

\section{Recommended Citation}

Friel, Alexandra J., "The Relationship between Within-Day Energy Balance and Menstruation in Active Females." Thesis, Georgia State University, 2010.

doi: https://doi.org/10.57709/1665431

This Thesis is brought to you for free and open access by the Department of Nutrition at ScholarWorks @ Georgia State University. It has been accepted for inclusion in Nutrition Theses by an authorized administrator of ScholarWorks @ Georgia State University. For more information, please contact scholarworks@gsu.edu. 


\title{
The Relationship Between Within-Day Energy Balance and Menstrual Status in Active Females
}

\author{
A Thesis Submitted to the Graduate Committee \\ in the Division of Nutrition at Georgia State University \\ in Partial Fulfillment \\ of the Requirements for the Degree \\ MASTER OF SCIENCE \\ IN \\ HEALTH PROFESSIONS \\ WITH AN EMPHASIS IN NUTRITION \\ Alexandra Joan Friel \\ Coordinated Program in Dietetics \\ Division of Nutrition \\ School of Health Professions \\ College of Health and Human Sciences \\ Atlanta, Georgia \\ 2010 \\ THESIS COMMITTEE \\ Dan Benardot, PhD, DHC, RD, LD, FACSM (Chair) \\ Walter R. Thompson, PhD, FACSM, FAACVPR \\ Anita Nucci, PhD, RD, LD
}




\section{APPROVAL}

THE RELATIONSHIP BETWEEN WITHIN-DAY ENERGY BALANCE AND MENSTRUATION IN ACTIVE FEMALES

By

ALEXANDRA FRIEL

Approved:

Dan Benardot, PhD, RD, LD, FACSM, Major Advisor

Walter R. Thompson, PhD, FACSM, FAACVPR, Committee Member

Anita Nucci, PhD, RD, LD, Committee Member 


\section{ACKNOWLEDGEMENTS}

This thesis would not have been possible without the guidance and support of my brilliant professors, family, and friends.

I wish to thank the following persons in particular:

Dr. Dan Benardot

to whom I am deeply indebted for his patience, counsel, and instruction throughout

Vincent and Florence Friel

my parents, for their constant encouragement and sense of humour

Edward deGrosbois

for his welcome advice and appreciated support

Marie deGrosbois

for being the role model of a true academic 


\section{AUTHOR'S STATEMENT}

In presenting this thesis as a partial fulfillment of the requirements for an advanced degree from Georgia State University, I agree that the Library of the University shall make it available for inspection and circulation in accordance with its regulations governing materials of this type. I agree that permission to quote from, to copy from, or to publish this thesis may be granted by the author or, in her absence, by the professor under whose direction it was written, or in his absence, by the Associate Dean, College of Health and Human Sciences. Such quoting, copying, or publishing must be solely for scholarly purposes and will not involve potential financial gain. It is understood that any copying from or publication of this dissertation which involves potential financial gain will not be allowed without written permission of the author.

Signature of Author 


\section{NOTICE TO BORROWERS}

All theses deposited in the Georgia State University Library must be used in accordance with the stipulations prescribed by the author in the preceding statement.

The author of this thesis is:

\section{Alexandra Friel \\ Coordinated Program in Dietetics \\ Division of Nutrition \\ College of Health and Human Sciences}

The Chair of the committee for this thesis is:

Dan Benardot, $\mathrm{PhD}$

Professor

Urban Life Building

Georgia State University

Atlanta, Georgia 30303

Users of this thesis who are not regularly enrolled as students at Georgia State University are required to attest acceptance of the preceding stipulation by signing below. Libraries borrowing this thesis for the use of their patrons are required to see that each user records here the information requested.

\begin{tabular}{|l|l|l|l|}
\hline NAME OF USER & ADDRESS & DATE & $\begin{array}{l}\text { TYPE OF USE (EXAMINATION } \\
\text { ONLY OR COPYING) }\end{array}$ \\
\hline & & & \\
\hline & & & \\
\hline & & & \\
\hline & & & \\
\hline
\end{tabular}




\title{
VITA
}

\author{
Alexandra Friel \\ 101 Livia Herman Way \\ Barrie, ON L4M 7K5 \\ Canada
}

2004-2009 Georgia State University

Bachelor of Science in Nutrition

Scholarship Athlete: Cross Country/Track \& Field

2009-2010 Georgia State University

Master of Science in Health Professions

Nutrition Concentration

Graduate Teaching Assistant: Dr. Dan Benardot

Dietetic Internship 


\section{ABSTRACT}

Background: Past studies suggest that inadequate energy intake (EI) is directly related to menstrual dysfunction (MD) in active females. Inadequate EI causes activation of the hypothalamic-pituitary-adrenal axis, disrupting the normal hormonal signaling of reproductive cycling and resulting in MD. However, studies have also demonstrated similar EI in athletes, but with different menstrual function. Traditionally, energy balance has been evaluated in 24-hour time periods. Recent research suggests there is benefit to analyzing energy balance at smaller intervals to better address physiologic response in real time. It is possible that women who meet their daily EI needs could still, therefore, experience MD if the majority of the day is spent in energy deficit.

Objective: The purpose of this study is to determine whether within-day energy balance is a factor in menstrual status in active adult females.

Methods: Twenty active females tracked hourly EI and energy expenditure over three days. A two-page survey was utilized to obtain information on training, health, and menstrual status. Participants were also asked to respond to several questions regarding eating habits and attitude towards food. Within-day energy balance was calculated and evaluated using NutriTiming ${ }^{\mathrm{TM}}$ software. Collected energy balance data were analyzed for associations with menstrual status.

Results: Participants spent more hours in a catabolic state (energy balance less than zero) than in an anabolic state (20.5 hrs vs $3.5 \mathrm{hrs}$ ) and averaged a caloric deficit of -504 kcal over 24-hours. Nine subjects (45\%) had experienced loss of menses for greater than 3 months (LoM $>3 \mathrm{mos}$ ), indicative of amenorrhea. Hours spent in energy surplus $>400$ kcal was inversely correlated with $\operatorname{LoM}>3 \operatorname{mos}(\mathrm{r}=-0.463 ; P=0.04)$. The impact of number of miles run per week and menstrual dysfunction, based on a quartile stratification of miles run, were analyzed using an ANOVA with Tamhane non-parametric post hoc test. Significant differences were found between the upper two quartiles of distance run per week and $\operatorname{LoM}>3 \operatorname{mos}(P=0.048)$. There was no relationship between end-of-day energy balance and Lom $>3$ mos.

Conclusion: Researchers and healthcare professionals would do well to examine energy balance in an hour-by-hour manner as it is has implications for MD. This would help to clarify whether within-day energy balance is a factor in $\mathrm{MD}$, and allow for the development of appropriate intervention strategies to improve health and athletic outcomes for active women. 


\section{TABLE OF CONTENTS}

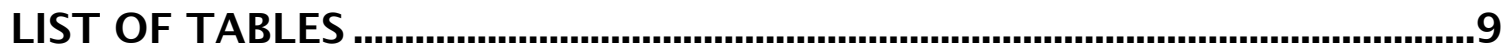

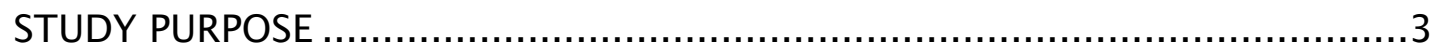

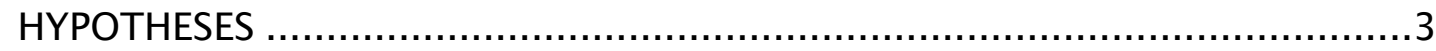

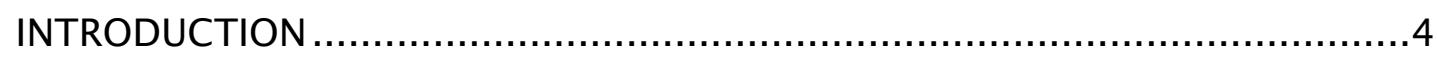

ENERGY INADEQUACY AND MENSTRUAL FUNCTION .............................24

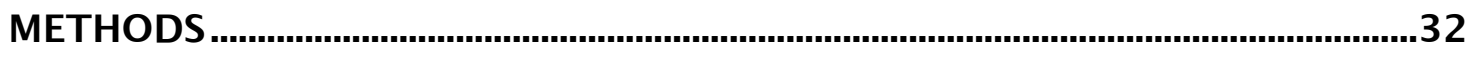

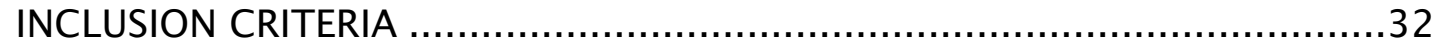

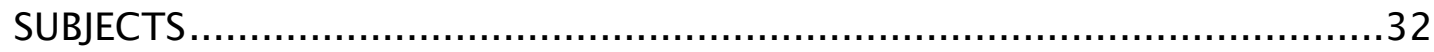

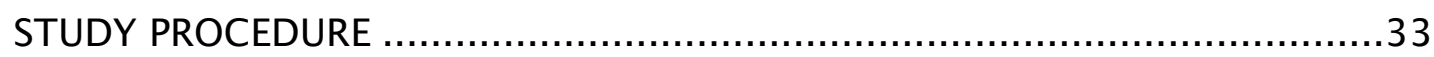

INSTRUMENTS

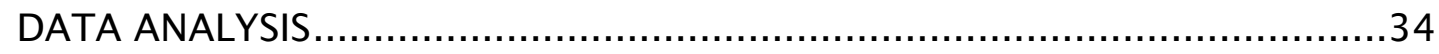

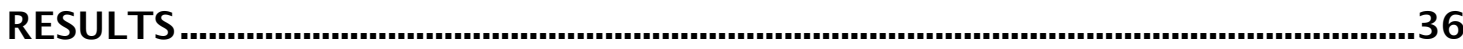

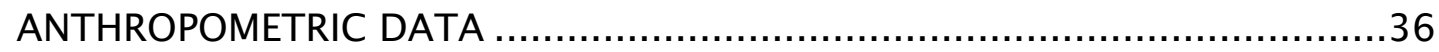

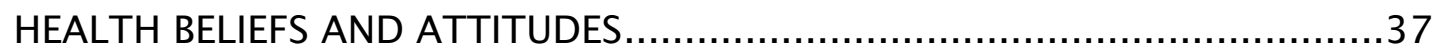

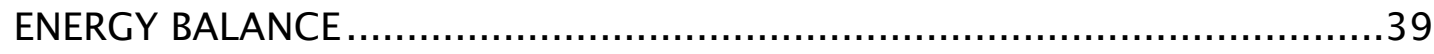

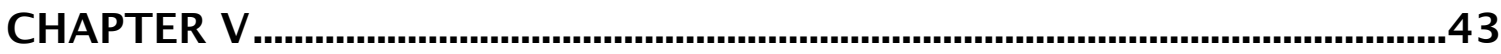

DISCUSSION AND CONCLUSIONS.......................................................................43

PREVALENCE OF LOSS OF MENSES AND LOW ENERGY INTAKE ...................43

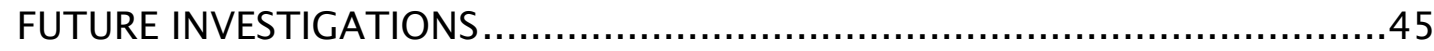

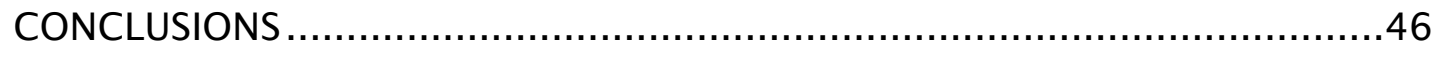

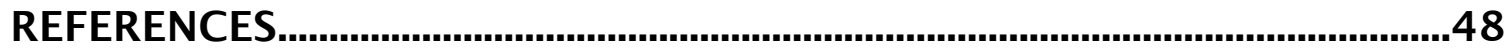

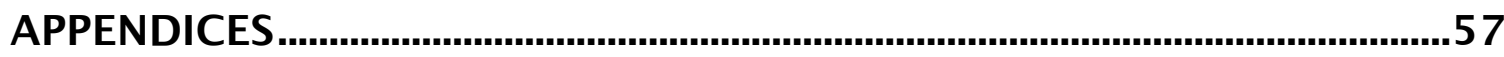

APPENDIX I : Research Questionnaire ...........................................................57

APPENDIX II: Data Entry Form ...........................................................................61

APPENDIX III: NutriTimingTM Example.................................................................63 


\section{LIST OF TABLES}

Page

TABLE I: Subject Characteristics

TABLE II: Perceived Impact of Regular Menstrual Patterns on Performance

TABLE III: Perceived Impact of Regular Menstrual Patterns on Health

TABLE IV: Dietary Intakes and Energy Balance 


\section{LIST OF ABBREVIATIONS}

$\mathrm{ACTH}$

ACSM

ADA

ANOVA

AVP

BMD

BMI

$\mathrm{CHO}$

$\mathrm{CRH}$

DRI

DC

ED
Adrenocorticotropin Releasing Hormone

American College of Sports Medicine

American Dietetic Association

Analysis of Variance

Arginine Vasopressin

Bone Mineral Density

Body Mass Index

Carbohydrate

Corticotropin Releasing Hormone

Dietary Reference Intake

Dietitians of Canada

Eating Disorder 


\begin{tabular}{|c|c|}
\hline FoM & Frequency of Menses \\
\hline FSH & Follicle-Stimulating Hormone \\
\hline GnRH & Gonadotropin Releasing Hormone \\
\hline hrs & Hours \\
\hline kcal & Kilocalories \\
\hline $\mathrm{kg}$ & Kilograms \\
\hline LBM & Lean Body Mass \\
\hline LH & Luteinizing Hormone \\
\hline LoM & Loss of Menses \\
\hline $\mathrm{m}$ & Meters \\
\hline $\mathrm{mg}$ & Milligrams \\
\hline NCAA & National Collegiate Athletic Association \\
\hline $\mathrm{OC}$ & Oral Contraceptive \\
\hline
\end{tabular}


SPSS

$\mathrm{T} 3$

U.S.

$\mathrm{VO}_{2 \text { peak }}$

Statistical Package for the Social Sciences

Triiodothyronine

United States

Peak Oxygen Uptake 


\section{CHAPTER I}

\section{INTRODUCTION}

Reproductive cycling is a hormonally-mediated, physiologic process that relies on a delicate interaction between the hypothalamus and pituitary gland (Golden \& Carlson, 2008). In healthy adults, menstrual cycling occurs in a regular and predictable manner with the majority of cycles falling within a 26 to 32 day range (Redman \& Loucks, 2005).

A number of environmental factors influence menstrual cyclicity. Low socioeconomic status, poor health, and inadequate nutritional intake have all been shown to have an inhibitory effect on menstruation (Anderson et al., 2003; Chumlea et al., 2003). Women who experience abnormally long cycles, or who fail to menstruate entirely, present with hormonal profiles that are associated with bone loss and infertility (Gambacciani et al., 2004). As bone density declines naturally with aging, this translates to a higher risk of premature osteoporosis and eventual fracture. The prevention of menstrual irregularity is therefore of considerable importance to all women, and particularly to competitive athletes for whom stress fractures are considered major sidelining injuries. 
When energy intake is not sufficient, hormonal shifts slow basal metabolism and nonessential body processes, such as reproduction, are sacrificed to ensure that scarce nutrients are utilized in the interests of survival (Loucks, 2007; Zanker, 2006; Tomten \& Hostmark, 2006; Manore, 2007; Loucks et al., 1998; Manore, 2004). Physical activity increases energy requirements that, if not met, impact the normalcy of reproductive cycling. Many athletes, especially those involved in energy costly endeavors, may find it difficult to consume food in adequate amounts (Loucks et al., 1998). In aesthetic and lean-build sports, individuals may purposefully choose to restrict intake in an attempt to modify weight and body composition (Ziegler et al., 1998). Both of these situations are common and athletes are frequently shown to have more incidences of menstrual disturbance than their sedentary counterparts.

Energy balance refers to the number of kilocalories (kcal) consumed within a given period of time relative to energy expended (Benardot, 2007). It has swift and direct endocrine effects. Energy balance is routinely studied in 24-hour segments yet the hormonal presentation within the body is highly dynamic and fluctuations occur in time increments much smaller than 24-hours. It is likely that analysis of energy balance in an hour-by-hour fashion would provide valuable insight into the nature of menstrual dysfunction in athletes. The purpose of this study is, therefore, to examine the prevalence of inadequate energy intake, measured in hours per day, and menstrual dysfunction in a small group of active females, and to describe the relationship between the two. 


\section{STUDY PURPOSE}

The purpose of this study is to determine whether within-day energy balance is related to menstrual status in active adult females.

\section{HYPOTHESES}

This study assesses hourly energy intake and expenditure in order to determine if withinday energy balance is related to loss of menses (LoM) for greater than three consecutive months.

Hypothesis 1: Large shifts in within-day energy balance are associated with reproductive dysfunction (LoM $>3$ months) in active females.

Null Hypothesis 1: Large shifts in within-day energy balance are not associated with reproductive dysfunction (LoM $>3$ months) in active females.

Hypothesis 2: Small shifts in within-day energy balance are associated with normal reproductive function (no history of LoM $>3$ months) in active females.

Null Hypothesis 2: Small shifts in within-day energy balance are not associated with normal reproduction function (no history of $\mathrm{LoM}>3$ months) in active females. 


\section{CHAPTER II}

\section{REVIEW OF LITERATURE}

\section{INTRODUCTION}

Female reproductive cycling is a process that is solidly based on normal endocrine function that is in turn affected by individual health. Active individuals who fail to adequately compensate for expended energy subject their bodies to additional stress. Consequently, endocrine function is altered and menstrual irregularities often result. The following is a review of current knowledge on the impact of energy deficiencies on menstrual function in the athletic population.

\section{MENSTRUATION}

\section{Normal Menstrual Cycling}

Estrogen (primarily circulated as estradiol) and progesterone are steroidal sex hormones that are produced in and released from the ovaries (Golden \& Carlson, 2008). These act 
upon the hypothalamus, triggering pulsatile emissions of gonadotropin-releasing hormone (GnRH). Secreted GnRH travels to the anterior pituitary via the hypophyseal portal system and initiates a corresponding release of luteinizing hormone (LH). Folliclestimulating hormone (FSH) is produced in a similar fashion and both hormones are necessary for follicular maturation (Ashley et al., 2000; Golden \& Carlson, 2008). This system as a whole is commonly referred to as the hypothalamic-pituitary-ovarian axis. Each menstrual cycle consists of two predominant phases. The follicular phase is generally regarded at the 'first phase' of menstrual cycling. Menses, which involves shedding of the uterine lining, occurs at the beginning of the follicular phase (Burrows \& Bird, 2000). As the follicular phase progresses, ovarian follicles develop into mature ovum. Rising levels of estrogen inhibit GnRH secretion and prepare the uterus for pregnancy (Ashley et al., 2000; Golden \& Carlson, 2008; Burrows \& Bird, 2000). Approximately halfway through a normal cycle, estrogen levels spike and its hormonal effect is suddenly promotional to the release of GnRH (Golden \& Carlson, 2008). The subsequent LH surge stimulates ovulation, and the progesterone-secreting corpus luteum is formed in the empty follicle (Burrows \& Bird, 2000; Ashley et al., 2000; Golden \& Carlson, 2008). This begins the luteal phase. If fertilization does not occur, the corpus luteum breaks down, progesterone levels decline, and menses is initiated (Ashley et al., 2000; Golden \& Carlson, 2008). 


\section{Menarche}

The first menstrual period, termed menarche, is typically reached around age twelve. Age at menarche is highly dependent on genetic factors, but is also heavily influenced by nutrition, health, and socioeconomic status (Anderson et al., 2003; Chumlea et al., 2003). Over the past century, age at menarche has declined as standard of living has improved and, it is postulated, as a consequence of overweight and obesity rates (Zacharias \& Wurtman, 1969; Anderson et al., 2003). However, these most recent data suggest that the current median menarcheal age in the U.S. is younger but not significantly younger than it was 30 years ago (Chumlea et al., 2003). In a national U.S. survey of 2510 females (ages 8-20 years) menarche was reached by $80 \%$ between the ages of 11.11 and 13.75 years, with 12.43 years being the median (Chumlea et al., 2003). Racial differences were noted with menarche tending to occur earlier in non-Hispanic blacks and Mexican Americans. This association appears to be inherent as it has been shown to be independent of weight for height (Anderson et al., 2003). It is worthwhile to consider menarcheal age a vital health sign in young females as menarche that is delayed several years beyond the norm is cause for concern (American Academy of Pediatrics, 2006).

A Turkish survey of 1017 high school girls provides a comparative look at menarcheal age and related factors in another setting (Ersoy et al., 2005). Researchers attempted to tease out specific factors related to menarcheal age by grouping the sample by socioeconomic class (using the Hollingshead index), physical activity, and nutritional intake (using a semi-quantitative food frequency questionnaire). These young girls were found to have reached menarche significantly earlier than their mothers (mean age 12.82 
versus 13.6 years; $P<0.001)$ but menarcheal age was not related to socioeconomic or physical activity grouping. Obese girls were more likely to commence reproductive cycling sooner than their normal weight classmates $(P=0.039)$. This is in agreement with other studies that have demonstrated similar associations between BMI and onset of menses (Anderson et al., 2003).

Menarche generally occurs later among the athletic population. The mean menarcheal age of U.S. college athletes is 13.3 years (13.4 years in lean build sports) compared with the current U.S. average of 12.43 years (Beals \& Hill, 2006; Chumlea et al., 2003). A recent survey of Croatian athletes underscored the effect of intense training on menarche. Researchers found that those who began sports participation prior to their first menstrual cycle achieved menarche significantly later than those who did not become competitive until after menarche (13.8 years versus 12.6 years; $P<0.001)$ (Dušek, 2001). A like finding was noted among adolescent ballet dancers. Dancers who began training after menarche experienced onset of menses at 12.1 years compared with 12.6 years for those who were trained prior to menarche (Castelo-Branco et al., 2006). Additionally, ballet dancers have been shown to trend towards older age at menarche when compared to nonathletic controls (Stokić et al., 2005).

Although the mean menarcheal ages themselves are in close range of one another, and would not constitute cause for concern within an individual, the trend of delayed menarche in athletes is certainly present. Failure to reach menarche by age sixteen represents the ninety-eighth percentile of menarche and, in this instance, medical advice should be sought (Golden \& Carlson, 2008). An individual with extremely delayed 
menarche should be evaluated for nutrition adequacy, illness, excessive exercise, and overall stress, all of which can disrupt normal hormonal signaling of the hypothalamicpituitary-ovarian axis (Burrows \& Bird, 2000). It is pertinent to note that while physical abnormalities of the genital tract are uncommon, a pelvic ultrasound may be warranted to rule out the possibility of an outflow disorder, such as a transverse septum, imperforate hymen, or other congenital malformations (Edmonds, 2006). In short, athletic activity is associated with, but is not a valid reason for, onset of menses outside of the normal age range.

\section{Abnormal Menstrual Cycling}

Excluding congenital abnormalities and pregnancy and lactation, menstrual irregularities occur when there is a disruption of normal endocrine signaling (Kalantaridou et al., 2004). The hypothalamic-pituitary-adrenal axis is responsible for the stress response in humans. Prolonged or frequent activation of this axis interrupts function of the reproductively involved hypothalamic-pituitary-ovarian axis. During periods of stress, survival is the biologic priority and it becomes useful to do away with the potentially energy costly processes (i.e. pregnancy and lactation) that fertility can incur (Chrousos et al., 1998; Kalantaridou et al., 2004). Multiple factors can induce a stress response and include, although are not limited to, psychological or emotional upset, over-exercise, and insufficient nutrition.

Leptin, a hormone released primarily from adipose tissue, interacts with the hypothalamus to communicate energy balance (Köpp et al., 1997; Fogteloo et al., 2004). 
It is likely then that leptin has a role in menstrual regularity. When the hypothalamicpituitary-adrenal axis becomes activated as a result of stress, corticotropin releasing hormone (CRH) and arginine vasopressin (AVP) are released from the hypothalamus (Chrousos et al., 1998; Kalantaridou et al., 2004). These hormones travel to the pituitary where they promote the secretion of adrenocorticotropic hormone (ACTH) which in turn stimulates cortisol release from the adrenal cortex. CRH in particular has been shown to reduce GnRH secretion as well as lower the ability of the ovaries to secrete steroid hormones (Zangeneh, 2009). Glucocorticoids, such as cortisol, impact female reproduction in a similar fashion (Sapolsky et al., 2000). Again, GnRH release is inhibited and subsequently so is the secretion of LH and FSH from the pituitary. Gonadal sensitivity to steroidal sex hormones may also be decreased and as a result, reproductive potential is curbed (Ding et al., 1988; Sapolsky et al., 2000; Zangeneh, 2009).

In general, all forms of reproductive cycling are classifiable into three broad categories (Golden \& Carlson, 2008; Warren \& Chua, 2008; The Practice Committee of the American Society for Reproductive Medicine, 2008):

- Eumenorrhea - Normal menstrual cycling; menarche is reached at an appropriate age and cycling occurs within a predictable and typical period of 26-35 days

- Oligomenorrhea - Abnormally long cycling; greater than 35 days between menses 
- Amenorrhea - Absence of menses; perhaps the most severe form of menstrual dysfunction, amenorrhea may be further defined as:

- Primary Amenorrhea - Failure to achieve menarche by age sixteen or,

- Secondary Amenorrhea - Loss of previously established menses for greater than 90 days

\section{Subclinical Menstrual Disorders}

Menstrual disorders may also be present in a subclinical form. Subtle changes in ovarian and gonadotropin hormone levels can result in cycles that have alterations of the luteal phase or are anovulatory in nature (De Souza et al., 2010). Anovulatory cycles are characterized by less than normal levels of estrogen during the follicular phase and show minimal to no rise of LH and progesterone. Since measurement of gonadal hormone levels requires blood or urine analysis, it is unusual for athletes to be evaluated for subclinical menstrual disorders. Consequently, researchers have suggested that the full extent of menstrual disturbance within the athletic population is likely greatly

underestimated (De Souza et al., 2010; Redman \& Loucks, 2004). 


\section{Prevalence of Abnormal Menstrual Cycling in Athletes versus Non-Athletes}

Prolonged loss of menses, outside of pregnancy, is relatively rare in the general population and has an incidence of approximately 2 to 5\% (Warren \& Chua, 2008; De Souza et al., 2010). However, among highly trained female athletes menstrual cycle disruptions are much more common (Manore, 2007; Beals \& Hill, 2006; Nattiv et al., 2007). Several studies have demonstrated that athletes who chronically end each day in energy deficit are more likely to suffer from irregular menstruation (Manore, 2007;

Redman \& Loucks, 2005; Gibson et al., 2004; Tomten \& Hostmark, 2006). It has been estimated that over half of all female distance runners experience amenorrhea and of those who maintain regular menstruation, as many as $78 \%$ have abnormal secretion of luteinizing hormone or fail to ovulate (Nattiv et al., 2007). Among generally active (noncompetitive) women, menstrual disturbance is more common in those who exercise $>2$ hours per week compared to sedentary controls (De Souza et al., 2010). This suggests that the problem of menstrual dysfunction is pervasive and inclusive of all exercising women, not just elite athletes.

A California survey of 589 female high school athletes found the prevalence of irregular or absent menstrual cycling to be $23.5 \%$ (Nichols et al., 2006). Since athlete age in this sample ranged from 13-18 years, it is possible that some of the reported menstrual irregularity was not related to athleticism but perhaps quite typical for females such a short distance from menarche. In Croatian athletes, prevalence of disordered menstrual cycling has been shown to be triple than of sedentary controls (Dušek, 2001). Menstrual dysfunction has a prevalence of $26 \%$ in the collegiate female population (Beals \& Hill, 
2006). Over half of the participants (56\%) in a small French study of recreational runners had some form of menstrual disturbance. Among female boxers, oligomenorrhea was reported by $54.6 \%$ whereas prevalence within a control group of recreationally active females was $\sim 6 \%$ (Trutschnigg et al., 2008).

Even if overt menstrual dysfunction is not present, subtle disruptions in hormonal signaling result in subclinical menstrual disorders characterized by short luteal phases or anovulation (De Souza et al., 2010; Loucks \&Thurma, 2003; Welt et al., 2004). Anovulatory cycles are fairly common within the first two to three years following menarche but beyond that are considered atypical (Slap, 2003; Golden \& Carlson, 2008; Warren \& Chua, 2008). Recently De Souza et al. (2010) quantified ovarian steroid hormone excreted in the urine of exercising women over the course of one to three menstrual cycles. Anovulation was assumed if LH and estradiol levels failed to rise sufficiently to stimulate ovulation or if progesterone levels were abnormally low. Data collected revealed that only $47.9 \%$ of exercising women were consistently ovulatory compared with $95 \%$ of sedentary women. Training load has been implicated as a contributing factor to abnormal menstruation (Dušek, 2001) however one must bear in mind that with increased physical exertion come increased nutrient needs which many athletes fail to meet. 


\section{ENERGY BALANCE}

\section{Macroutrient Needs}

A review by Manore (2004) suggests that a diet of $1800 \mathrm{kcal} /$ day or less is not enough to provide adequate nutrition and can affect menstrual function. Calorie needs can reach $4000 \mathrm{kcal} /$ day for female endurance athletes, although intakes in the range of 2300-2500 kcal are sufficient for most athletes. The American Dietetic Association (ADA), Dietitians of Canada (DC) and the American College of Sports Medicine (ACSM) (2009) have jointly issued specific dietary recommendations for athletes. Protein requirements vary from 1.4 to $1.7 \mathrm{~g} / \mathrm{kg}$ body weight and can be met easily through a healthy varied diet, without the use of supplements. Athletes concerned about body composition may be more inclined to shy away from fat-containing foods. However, fat is a necessary nutrient and should comprise approximately 20 to $35 \%$ of the diet. Optimal carbohydrate (CHO) intake ranges from 6 to $10 \mathrm{~g} / \mathrm{kg}$ of body weight per day. Manore's 2001 review suggests that the majority of athletes fail to meet even the minimum requirements for carbohydrate intake, with most consuming $<6 \mathrm{~g} / \mathrm{kg}$ per day. Only three of the twelve studies examined by Manore reported adequate levels of carbohydrate intake. The ADA, DC and ACSM recommend that:

- Athletes consume a high carbohydrate pre-exercise meal or snack

- Athletes consume 30 to $60 \mathrm{~g}$ of $\mathrm{CHO}$ per hour during exercise

- Athletes consume 1 to $1.5 \mathrm{~g} \mathrm{CHO}$ per kg body weight within 30 minutes postexercise 
Dietary approaches such as this would minimize large shifts in energy balance and maintain adequate levels of blood glucose.

\section{Micronutrient Needs}

There is evidence that micronutrient needs, particularly minerals, are increased in athletic individuals (Chinevere et al., 2007). In developed countries, vitamin deficiencies are rare in athletes and non-athletes alike, (Maughan, 1995) but those who train for long durations or in warm environments can incur substantial losses of copper, zinc and iron. Athletes who exercised for 30 minutes $\left(50 \% \mathrm{VO}_{2 \text { peak }}\right)$ in a $23^{\circ} \mathrm{C}$ environment experienced iron loss through sweat at a rate of $0.33 \mathrm{mg} / \mathrm{h}$ (DeRuisseau et al., 2002). It is possible that the body employs conservation mechanisms to impede mineral sweat losses after 60 minutes of exercise as sweat concentrations of both iron and zinc have been shown to be lower beyond this time point (DeRuisseau et al., 2002; Montain et al., 2007). However, researchers are in disagreement as to whether this observation is independent of sweat rate or if a dilutional effect takes place (DeRuisseau et al., 2002; Montain et al., 2007). Given that the recommended iron intake for U.S. women (age 19-30 years) is $18 \mathrm{mg} /$ day, losses of this amount represents an increased need of only about $1.8 \%$. Over time, athletes who do not replace lost minerals (i.e. fail to consume a sufficient diet) or who exercise for longer periods, or in hot environments put themselves at greater risk of acquiring a performance impacting deficiency. 


\section{The Physiologic Response and Energy Balance}

\section{Thermic Effect of Feeding}

Energy balance refers to the number of kilocalories consumed within a given period of time relative to energy expended (Benardot, 2007). Traditionally, energy balance is evaluated in 24-hour increments, where an individual in energy balance would spend and consume kilocalories in equal amounts. Recently, researchers have suggested that there is a benefit to analyzing energy balance and/or nutrient intake at smaller time intervals as it better addresses physiologic need in real time (Duetz et al., 2000; Benardot, 2007; Symons et al., 2009). Isocaloric diets that vary in macronutrient composition have strikingly different effects on the body's thermogenic response (Labayen et al., 1999; Feinman \& Fine, 2004). For example, the thermogenic cost of a high protein diet is greater than that of a calorically identical high carbohydrate diet and therefore is more conducive to weight management (Feinman \& Fine, 2004). Similarly, the thermic effect of food may be more or less depending on the frequency and regularity of nutrition delivery (Farschi et al., 2004). In essence, the body's response to energy intake is not a caloric calculation made each day at midnight but rather is dynamic and highly changeable.

The body will more efficiently process (i.e. the thermic effect will be lesser) $1000 \mathrm{kcal}$ delivered in one meal than the same caloric amount delivered in four meals (LeBlanc \& Diamond, 1986). This has been demonstrated in mongrel dogs confined to calometric 
cages and fed either small or large meals at varying frequency. Following each meal, respiratory quotients and $\mathrm{VO}_{2 \text { peak }}$ were observed. Researchers noted that "postprandial energy expended was twice as large when meal frequency was increased" suggesting that small, frequent feedings are more energy costly and are therefore be more conducive to a lean body composition.

Another study, this time in adult humans, showed greater oxygen consumption (26\% versus $18 \%$ increase) after ingestion of four small meals compared with ingestion of one, calorically identical large meal $(P<0.05)$ (LeBlanc et al., 1993). Additionally, carbohydrate utilization was shown to be greater with the frequent feeding pattern $(P=$ 0.04), a potential boon to athletes. In a longitudinal population survey of 2375 adolescent females, consumption of three or more meals per day was strongly associated with lower BMI z-scores $(P=0.0001)$, furthering the likelihood that within-day energy balance affects the body's utilization of ingested food (Franko et al., 2007).

Not all of the literature supports these conclusions (Tai et al., 1991). On two different days, seven healthy women (age 23-30 years) were assigned to receive either a $750 \mathrm{kcal}$ liquid meal in a single quantity or split into six small portions given at 30-minute intervals. Contrary to the findings of LeBlanc et al., thermic effect of food was higher when the meal was ingested as a bolus $(P<0.05)$. A later review of available energy balance literature concluded that such studies were highly subject to a host of confounding factors making it difficult to ascertain whether meal frequency had any significant impact on total day energy expenditure (Bellisle et al., 1997). 
Despite this, a more recent study of nationally competitive gymnasts and runners established that those who stayed within an energy balance of $\pm 300 \mathrm{kcal}$ tended to be to be leaner than those who spent more hours per day in energy deficits outside of this range $(\mathrm{r}=0.407 ; P=0.001)$ (Duetz et al., 2000). Given the sheer volume of kilocalories required by an elite athlete in one day, the maintenance of such a narrow energy balance could only be achieved by ingestion of numerous meals. It should be noted that differences in body composition were seen despite the fact that all athletes met their energy needs at the 24-hour mark.

\section{Leptin Response}

Energy balance and meal patterning influence the amplitude and timing of leptin secretion, which in turn influence menstrual function (Köpp et al., 1997; Fogteloo et al., 2004; Bergendahl et al., 2000). Low leptin levels have been associated with loss of menses in energy restricted individuals; maintenance of normal leptin secretions may therefore improve menstrual functioning (Köpp et al., 1997). A small study of healthy females $(n=8)$ demonstrated similar patterns of daily leptin release regardless of whether an individual was fed or fasted (Bergendahl et al., 2000). Despite maintenance of normal leptin release patterning, the concentration of serum leptin was significantly lower during a short duration fast of 2.5 days $(P=0.0007)$. The potential exists that individuals who skip meals throughout the day (arguably another form of short duration fasting) could lower their leptin levels and subsequently see an alteration in menstrual function. 
A Dutch study recently confirmed that meal patterning has effects on leptin secretion (Fogteloo et al., 2004). Increasing frequency of meals from three to eight times daily in two separate 4-day interventions reduced the amplitude of leptin secretion in five obese but otherwise healthy women. Although it is low leptin levels that are associated with loss of menses, this study clearly shows that leptin is affected by meal patterning. Given that the sample studied was obese, it is not likely that the leptin reduction was damaging as leptin levels are directly related to adiposity. Rather, it may actually reflect the beginnings of a favorable shift in body composition or simply a more stabilized leptin secretion in response to a healthier feeding pattern.

\section{Prevalence of Sub-Optimal Energy Intake}

Athletes frequently consume less than their required energy needs (Hassapidou \& Manstrantoni, 2001; Leblanc et al., 2002; Beals \& Hill, 2006; Tomten \& Hostmark, 2006; Ziegler, 2006). Dietary analysis of elite Greek female volleyball players, middle distance runners, ballet dancers, and swimmers revealed that all groups, with the exception of volleyball players during their competitive season, were not meeting their daily energy needs (Hassapidou \& Manstrantoni, 2001). This particular study was made up of thirtyfive athletes and ten controls, all 18 to 26 years of age. In an effort to obtain the most accurate data, seven-day weighted food records were kept once during a competitive season and again during a non-competitive season. Energy intake was found to be similar in both athletes and controls; however athletes had significantly greater energy 
expenditure and were more likely to present with total day negative energy balance.

Furthermore, iron intake was found to be low for all teams, which puts athletes at risk of developing iron-deficiency anemia.

It is not definitively known why athletes under-consume energy, but it is possible that athletes find it difficult to take in food in such large amounts or do so in a purposeful attempt to modify body composition (Loucks et al., 1998). Indeed the latter may be the more likely scenario when one considers that approximately one-third of adolescent ballet dancers (Castelo-Branco, 2006) and U.S. collegiate athletes (Beals \& Hill, 2006) report adhering to a weight control diet. The belief that an ideal weight is necessary for performance is widely held among ballet dancers ( $87 \%$ of a 2006 survey) which could explain the prevalence of restrictive eating behavior.

A survey assessment of eating behaviors and self-perception among national level U.S. junior figure skaters revealed that $80 \%$ of females viewed themselves as normal weight or underweight, yet $79 \%$ of that same sample wished to lower their weight (Ziegler et al., 1997). Four-day food records suggested that this group was actively trying to engage in weight loss as intake averaged a mere $1422 \mathrm{kcal}$ per day. A later study by Ziegler et al. (2006) evaluated 3-day food records from 122 young, female synchronized skaters and found similar evidence of under nutrition. Based on dietary reference intakes (RDI) as established by the National Academy of Sciences, energy needs were estimated to be in the range of $2200-2500 \mathrm{kcal}$ per day. They found that the skaters fell short of this by $544-844$ kcal per day. Calcium and iron intake were also below the RDI with the athletes achieving only sixty-five and eighty-seven percent of the RDI for each mineral, 
respectively. These two studies, although separated by almost a decade, present an interesting picture of U.S. skaters. Their self-perception is quite accurate, but the belief system seems to follow a flawed thought process that less food is synonymous with less weight, which is synonymous with better performance.

Beals and Hill (2006) surveyed collegiate athletes on eating habits and menstrual function over two competitive seasons. Participants were recruited from diving, cross-country, field hockey, softball, swimming, tennis, and track and field teams. Disordered eating behavior was found to be present in $28 \%$ of the sample, that is, the athletes self-reported diagnosis of an eating disorder, believed they had an eating disorder, or were dissatisfied with their weight and engaged in at least one pathogenic weight control behavior. Similar to the ballet dancers, $36 \%$ of the collegiate athletes restricted energy intake as a means of achieving a particular weight. A conservative estimate of actual daily needs would likely be in the range of 2300-2500 kcal (Manore, 2004), which is much higher than what is generally thought of as a calorie-restricted diet (1200-1800 kcal). These numbers are estimations and the dietary data presented here are qualitative in nature but this does highlight a seemingly pervasive notion that athletic performance is dependent on strict dietary control.

A three-year prospective study in France examined 180 adolescent male soccer players and reported inadequate energy intake for all subjects involved (LeBlanc et al., 2002). These athletes were younger, with ages ranging from 13 to 16 years. Once annually, anthropometric data were collected and players recorded five days worth of dietary intake. Calculated daily energy deficits ranged anywhere from $1467-1790 \mathrm{kcal}$. This 
study looked only at males, but it seems to suggest that the problem of sub-optimal energy intake begins early and is a common feature of all athletic individuals.

Although dietary inadequacy is widespread among athletes, dietary supplements are frequently used. Sixty-seven percent of young German athletes and $40 \%$ of U.S. synchronized skaters report current use of dietary supplements (Ziegler \& Jonnalagadda, 2006; Braun et al., 2009). Given that the primary reasons for supplement use include improved health, performance, and to ensure adequate dietary intake, it seems that athletes intuitively know they are not consuming enough (Ziegler \& Jonnalagadda, 2006; Braun et al., 2009). Perhaps the placebo effect provided by a pill is far more enticing than food. Unfortunately, the failure to meet intake goals in the athletic population is particularly troublesome when one considers that energy intake is linked with micronutrient intake, and athletes who restrict their diet put themselves at greater risk of deficiencies.

\section{Commonly Affected Sports}

Classically, lean build sports are the ones thought to be at highest risk of eating disordered behavior and inadequate energy intake. In 2002 Hausenblas and Carron reviewed fourteen studies of eating behaviors in female athletes. Of those, nine studies confirmed and five studies negated the traditional view of elevated eating disorder risk in weight conscious sports (Hausenblas \& Carron, 2002). A later survey by Williams et al. (2006) found no difference in indices of cognitive restraint regardless of whether an 
athlete competed in an aesthetic, non-aesthetic, team, or individual sport. By contrast, a survey that consisted of the total population of elite Norwegian athletes revealed that significantly more lean-sport athletes reported menstrual dysfunction compared with nonlean sport athletes and controls (Torstveit \& Sundgot-Borgen, 2005). A similar survey of seventy-two Croatian athletes and ninety-six non-athlete controls found a higher prevalence of secondary amenorrhea in the athlete group (30\% versus 13\%) (Dušek, 2001). Additionally, secondary amenorrhea was more frequently seen in middle and long distance runners $(65 \%)$ than short distance runners (21\%). Assuming the menstrual dysfunction resulted from inadequate energy intake, this would be in line with the traditionally accepted lean-sport, low-intake archetype. In endurance sports, which are classified as lean, large caloric deficits may be more likely to occur simply because energy demand is so great (Manore et al., 2007; Loucks, 2007). Regardless of sport, inadequate energy intake is prevalent among all athletes and the potential for improvement following dietary correction is high.

\section{Body Composition}

The body compensates for inadequate energy intake by lowering its basal metabolic rate, which can result in underestimations of an athlete's true energy needs (Loucks, 2007). Lean body mass, the most metabolically active tissue, is used as an energy substrate in an adaptive response to simultaneously satisfy kcal requirements and reduce baseline energy needs (Shils et al., 2006). These metabolic adaptations make the body an extremely 
efficient user of calories (Loucks, 2007). In other words, weight may be maintained or gained on fewer calories than would otherwise be expected. This can make it difficult for athletes to achieve optimal body composition while loss of menses puts the individual at risk of developing significant health problems, particularly loss of bone mineral density (BMD) (Beals \& Hill, 2006; Manore et al., 2007; Wiksten-Almströmer et al., 2009).

The reasons for inadequate intake are diverse but often include disordered eating behaviors, insufficient biological drive to eat, and attempts to modify body composition. Interestingly, in the Deutz et al. study (2005) that within-day energy balance deficits of -300 kcals or more were associated with higher percent body fat in elite gymnasts and runners. Conversely, athletes who spent more time in energy surplus, tended to be leaner and have lower body fat percentages. Individuals who over restrict energy intake may actually worsen body composition as the body adjust basal metabolism downwards. In order maintain health and achieve optimal body composition, physically active women should be encouraged to know their nutritional needs and eat accordingly.

A study by Williams et al. (2006) examined the relationship between menstrual cycle length and attitude towards food. Study participants included 151 female Division I and club athletes from a variety of sports and 70 non-athlete controls. The Eating Disorder Inventory and survey questionnaires were used to obtain information on diet patterns, physical activity and menstrual status. Researchers found that irregularly cycling athletes were at increased risk of disordered eating and showed higher cognitive restraint than normally cycling athletes. Athletes were more likely to report having long menstrual cycles than non-athletes. The authors speculate that irregularly cycling athletes may be 
consciously ignoring bodily cues of hunger in order to restrict caloric intake. Caloric restriction could in turn lead to significant energy deficits and reproductive suppression (Manore, 2004).

\section{ENERGY INADEQUACY AND MENSTRUAL FUNCTION}

As previously discussed, menstrual cycle disruptions occur when there is abnormal hypothalamic secretion of GnRH (Warren \& Chua, 2008). The ensuing domino effect is one of sporadic LH release, diminished stimulation of the ovaries, and a decline in estradiol and progesterone (Zanker, 2006; Warren \& Chua, 2008). The hormonal mechanisms that trigger this cascade of events have yet to be certainly identified though it is plausible that declining leptin levels, a consequence of energy insufficiency and resultant fat loss, play a central role (Zanker, 2006; Welt et al., 2004; Misra M et al., 2004; Warren \& Chua, 2008). Baseline circulating leptin levels are directly related to adiposity (Köpp et al., 1997; Fogteloo et al., 2004; Chrousos et al., 1998; Kalantaridou et al., 2004). Anything beyond this is related to eating patterns, and leptin levels will fluctuate with meals in much the same way insulin would. Thyroid hormone triiodothyronine (T3), involved in the regulation of metabolic rate, is understandably decreased in periods of energy depletion and is likely also involved in cessation of menses (Zanker, 2006; Welt et al., 2004; Misra M et al., 2004). In a study by Welt et al. (2004), T3 levels rose with leptin dosing, similar to the way both hormones would rise with increased caloric intake. The combined effect of in both hormones, which correspond positively with energy intake, is worth considering. 
Increased physical activity alone does not have a negative effect on the female athlete's reproductive cycle (Loucks \& Thurma, 2003). Irregularities occur only when an energy deficit exists. A cohort of sedentary, eumenorrheic women were recruited to participate in trials, each several months apart, during which they expended $15 \mathrm{kcal} / \mathrm{kg}$ lean body mass (LBM) for five days during their follicular phase. One of the trials was performed in energy balance with women receiving $45 \mathrm{kcal} / \mathrm{kg} \mathrm{LBM}$. The other trial was performed in an induced energy deficient state. Women were provided with 30,20 , or $10 \mathrm{kcal} / \mathrm{kg}$ LBM. Following each trial period blood samples were collected to determine LH pulsatility. This was done in an in-patient setting at 10-minute intervals for 24-hours. The results of this tightly controlled study clearly demonstrated that LH secretion is disrupted when energy availability falls below $30 \mathrm{kcal} / \mathrm{kg}$ LBM. Specifically, LH pulse frequency was decreased while amplitude was increased. All subjects engaged in identical exercise strain during both periods of energy adequacy and energy deficiency. LH pulsatility was altered only when intake was drastically lower than needs thus furthering the likelihood that intake more so than training modifications should be employed as interventions to hypothalamic amenorrhea.

Despite significant evidence for inadequate intake as root cause of hypothalamic amenorrhea, other studies have found similar or only slight differences in daily intake of energy and macronutrients between regularly and irregularly menstruating women. A small French study had 21 runners track seven days of dietary intake and complete a questionnaire on training and menstrual status at four time points over one-year (Rosetta et al., 2001). No differences in training or energy intake were noted between women 
grouped by menstrual status. In another study, 20 regularly and irregularly menstruating female runners were matched by age and performance (Tomten \& Hostmark, 2006). To assess energy balance, energy expenditure during exercise was determined via indirect calorimetry and heart rate monitors were worn during one full week of training. A 3-day weighed food record was kept by each athlete. Serum measures of LH, FSH, cortisol, and estradiol were taken during follicular phase of eumenorrheic athletes and at random time points for amenorrheic athletes. No differences in cortisol levels were noted between the two groups and the amenorrheic women took in slightly, but not substantially, fewer calories. It should be noted that all of these studies looked at energy and macronutrient intake in 24-hour time blocks. None of the reviewed literature accounted for within-day differences, that is, hour-by-hour differences, in energy balance. Doing so would better consider real-time endocrine function and its effects on energy and substrate metabolism (Benardot, 2007). As the Deutz et al. study (2000) showed, individuals can end a day in near perfect energy balance and yet still present with strikingly different body composition profiles. The same may also be true of metabolic and endocrine profiles. The interests of science and research would be better served by energy analyses conducted in much smaller time blocks. 


\section{Health Implications of Abnormal Menstrual Cycling}

\section{Bone Health}

Unmet energy needs can cause the body to conserve energy, bypassing any process not deemed absolutely necessary. Estrogen is an osteoprotective sex and is decreased in individuals who fail to meet their nutrient needs (Gambacciani et al., 2004). Low levels of circulating estrogen result in disinhibition of osteoblastic activity and a high rate of bone turnover. Compromised bone integrity may result. Significant bone mineral loss or failure to reach an appropriate level of peak bone mass by early adulthood increases the risk of premature osteoporosis and fracture in athletes (Nattiv et al., 2007).

Beals and Hill (2006) examined menstrual function and BMD 112 female collegiate athletes from seven different sports. Menstrual irregularities were found to be most common among athletes participating in lean-build sports, although no athlete was found to have BMD that would indicate osteoporosis as defined by the World Health Organization (T-score -2.5). The ACSM notes that "the fracture rate doubles for each reduction of one standard deviation in BMD [and] loss of BMD may not be fully reversible"(Nattiv et al., 2007). Based on this, the ACSM recommends more stringent values be used during health screening. Z-scores below -1.0 should indicate a high risk athlete and Z-scores under -2.0 should be viewed as low BMD. In the Beals and Hill study, two cross-country athletes were found to have spinal BMD below -2.0 and eleven athletes had BMD values below -1.0. This suggests that low BMD is common, and root cause needs to be addressed. 
There is sufficient evidence to support a relationship between elevated cortisol levels, irregular menstruation and reduced bone density. Cortisol dips and peaks naturally over a 24-hour period and usually increases with endurance exercise (Dennison et al., 1999; Tabata et al., 1991). In a study of 71 active women, cortisol levels were highest, and BMD values were lowest, in the amenorrheic individuals (Ding et al., 1988). Other investigations have demonstrated that normal weight and normally menstruating women have favorable cortisol and BMD values, while individuals suffering from anorexia nervosa have significantly higher cortisol and lower BMD (Lawson et al., 2009). Interestingly, amenorrheic women of normal weight present with cortisol and BMD measures that fit comfortably in between these two extremes (Lawson et al., 2009). Cortisol has also been shown to be predictive of BMD in adult men (Çetin et al., 2001; Dennison et al., 1999). In elderly men, those with relatively shallow cortisol dips were more likely to experience bone loss over a four year period than those with deeper dips (Dennison et al., 1999). Elevated cortisol has roots in energy availability. This has been demonstrated in exercising athletes who experienced rising levels of plasma cortisol when made to exercise without carbohydrate supplementation compared with no change in plasma cortisol when supplementation was provided (Tabata et al., 1991). It would appear that most factors related to menstrual dysfunction in athletes, that is, low BMI, low body fat, and high cortisol levels, are consequences of inadequate energy intake. 


\section{Pharmacological Treatment}

It is not uncommon for athletes to report use of hormonal medications with the intention of restoring menses and, it is assumed, protecting bone health (Torstveit \& SundgotBorgen, 2005; Beals \& Hill, 2006). The thought process is understandable but the literature is fairly mixed. A ten cycle oral contraceptive (OC) study on women with hypothalamic amenorrhea and baseline osteopenia showed significant improvements in lumbar spine BMD following treatment (Warren et al., 2005). On the other hand, amenorrheic ballet dancers who received OC medication for two years had no improvements in BMD compared with amenorrheic dancers who received a placebo, and both groups remained lower than a control group (Warren et al., 2003). In eating disordered individuals, six cycles of OC treatment resulted in a greater increase in lumbar spine BMD than that of controls (Strokosch et al., 2006). The initial increase in BMD was promising but unfortunately was not sustained and no difference was noted between groups at cycle thirteen (Strokosch et al., 2006). Another study found a small but significant increase in patients treated with recombinant human insulin growth factor-1 but not among those given OC or a placebo (Grinspoon et al., 2002). Even in healthy young women, the influence of $\mathrm{OC}$ on BMD is still not definitively known with researchers typically turning up negative effects (Prior et al., 2001; Shoepe \& Snow, 2005) or no effects (Reed et al., 2003; Nappi et al., 2003).

Where estrogen therapy has proved inconclusive at best, leptin therapy may succeed. Three months of twice daily subcutaneous leptin administration improved indices of normal menstrual cyclicity and showed potential for improving bone density (Welt et al., 
2004). Those who received the recombinant human leptin saw more instances of follicular growth and ovulation over three months than did a control group. Additionally, there appeared to be a dose dependent response as follicular development was more pronounced in those receiving higher doses of leptin. Osteocalcin, a protein generally associated with osteoblastic activity, was increased although overall bone density did not significantly change. Future studies would do well to examine the potential bone benefit that leptin supplementation may provide. Appetite decreases associated with leptin therapy should not be ignored as this could prove to be a disastrous side effect if this treatment is used in patients suffering from psychometric eating disorders.

\section{Effects of Weight Gain}

Increasing energy intake is by far the best treatment intervention for individuals with low bone density and hypothalamic amenorrhea. Bolton et al. (2004) found that for each unit of BMI recovered by anorexics there was a corresponding $26 \mathrm{~g}$ increase in total BMD and $0.4 \%$ increase in lumbar spine BMD. Additionally, nutrition therapy in the form of simple nutrition counseling has been shown to produce improvements in spine, hip and total BMD in as little as two months (Dominguez et al., 2007). The prevalence of low energy intake in the athletic population suggests that it is not so much the result of a psychometric disorder as it is a knowledge deficit. Applying nutrition interventions in this population would be potentially less challenging and yet still do a great deal to reduce fracture risk and improve overall health. 


\section{Within-Day Energy Balance and Menstruation}

Many female athletes who experience reproductive irregularities do not engage in disordered eating behaviors and, when energy balance is analyzed at the 24-hour mark, have dietary intakes similar to that of their eumenorrheic counterparts (Rosetta et al., 2001; Tomten \& Hostmark, 2006). Findings related to 24-hour energy balance are therefore informative but fail to account for all cases of irregular menstruation as a multitude of factors contribute to maintenance of female reproductive health. Likewise, studies on body composition (lean mass versus fat mass) have revealed a correlation between low body fat and irregular menstruation (Stokić et al., 2005; Castelo-Branco et al., 2006) but have failed to produce a universally accepted value that can be applied to female athletes as a whole. Other studies have reported similar levels of body fat in regularly and irregularly cycling individuals leaving the validity of this association in question (Coiro et al., 2006). Inconsistencies within the literature suggest that we are missing an unknown factor. As of yet, no research has examined the relationship of within-day energy intake and expenditure to menstruation. It is possible that large fluctuations in caloric balance, such as front- or back-loading daily energy intake, also results in menstrual irregularities. 


\section{CHAPTER III}

\section{METHODS}

\section{INCLUSION CRITERIA}

Individuals were eligible for inclusion only if they were active a minimum of 3-4 days per week (i.e., every other day) and 19-30 years of age. Participants agreed to complete a two-page health, demographic and training questionnaire, and recorded energy intake and expenditure for a total of three days. Procedures were approved by Georgia State University’s Institutional Review Board.

\section{SUBJECTS}

Subject recruitment was accomplished through contact with collegiate coaches, via mass e-mail, and by word-of-mouth. Twenty-nine eligible participants responded as interested. Twenty subjects completed the full study protocol. The study population consisted of ten recreationally active women, two amateur tri-athletes, one competitive marathon runner, and seven NCAA division I collegiate middle-distance runners. For the purposes of this study, menstrual dysfunction was defined as any of the following:

- Presence of primary amenorrhea

- Frequency of menses equal to zero 
- Loss of menses $>3$ months

Given the age of the study sample (19-30 years) presence of primary amenorrhea is unlikely. This is, therefore, primarily an investigation of secondary amenorrhea.

\section{STUDY PROCEDURE}

Subjects were provided with either an electronic or hard copy version the necessary study forms. This was done based on subject preference. All subjects met with the principle investigator at least once and anthropometric data were collected at that time. At the conclusion of the study, completed study forms were returned to the investigator either in person via postal service in a stamped, preaddressed envelope (provided to participants who opted to receive hard copy study forms).

\section{INSTRUMENTS}

Participant height was measured in centimeters to the nearest tenth using a Martin-type portable anthropometer (stadiometer). Weight was measured in pounds to the nearest tenth using a Tanita scale (Arlington Heights, Illinois USA). This was later converted to kilograms.

A two-page survey consisting of open- and close-ended questions was used to obtain information on training, health, and current and past menstrual status (Appendix I). 
Participants were also asked to respond to questions regarding eating habits and attitude towards food.

Hourly energy intake and expenditure was recorded on one highly active day, one moderately active day and one non-active day using the NutriTiming ${ }^{\mathrm{TM}}$ Data Entry Form (Appendix II). In order to accurately determine energy expenditure, participants were asked to assign an activity factor to all daily activities using a scale of 1 (resting, reclining) to 7 (exhaustive). Collected energy balance data were then entered and evaluated using NutriTiming ${ }^{\text {TM }}$ software.

All participants signed letters of informed consent and retained a copy of the consent form for their records.

\section{DATA ANALYSIS}

Dietary intake data were analyzed on each subject using NutriTiming ${ }^{\mathrm{TM}}$ software (nutrient analysis based on USDA Version 21 Standard Nutrient Database) to assess end-of-day and within-day (hourly) energy balance (see Appendix III for sample output). Within-day energy balance was evaluated based on each subject's greatest caloric surplus, greatest caloric deficit, hours in energy surplus $>400$ kcals, hours in energy deficit $<400$ kcals, hours anabolic (energy balance greater than zero) and hours catabolic (energy balance less than zero). 
Statistical analyses were performed using SPSS software, version 12.0. Based on the small sample size $(n=20)$, abnormal distribution of the data were assumed and analyses were, therefore, conducted using non-parametric statistical methods. The menstrual cycle characteristics between oral contraceptive users versus non-users were evaluated via independent samples Student's t-test. The Spearman's rho test assessed for potentially significant correlations within the data. The impact of number of miles run per week and menstrual dysfunction, based on a quartile stratification of miles run, were analyzed using a non-parametric post-hoc analysis of variance (ANOVA). In all cases, statistical significance was set at $\mathrm{P}<0.05$. 


\section{CHAPTER IV}

\section{RESULTS}

\section{ANTHROPOMETRIC DATA}

Of the 29 individuals who indicated initial interest, 20 completed the study in full.

The subject population was comprised of 20 recreationally active and athletically competitive women. Ten subjects were active but non-competitive, 2 were tri-athletes, 1 was a competitive marathon runner, and 7 were collegiate cross-country runners. The mean age of study participants was 23.35 years $( \pm 3.13)$. Mean height, weight and body mass index (BMI) were found to be $166.59 \mathrm{~cm}( \pm 7.96), 60.73 \mathrm{~kg}( \pm 6.86)$ and $21.83 \mathrm{~kg} /$ $\mathrm{m}^{2}( \pm 1.85)$, respectively. Running activity was performed by participants $0-7$ days per week with the sample averaging 4.18 days per week $( \pm 2.16)$. On average the sample engaged in strength training 1.88 days per week $( \pm 0.65)$.

All subjects had previously achieved menarche and average age of occurrence was 12.89 years $( \pm 1.94)$. Two subjects reported occurrence of menarche at $>15$ years of age, indicating a history of primary amenorrhea. Nine subjects (45\%) had experienced LoM $>3$ months and two subjects $(10.5 \%)$ indicated a previous medical diagnosis of 
amenorrhea. Twelve subjects $(60 \%)$ reported current use of oral contraceptives and seven subjects $(35 \%)$ reported a history of OC use as a means of inducing or regulating menses. Three participants (15\%) reported having past diagnosis of an eating disorder. There were no significant anthropometric differences between the total sample and subjects with a history of LoM $>3$ months, diagnosis of ED or diagnosis of amenorrhea. Subject characteristics are presented in Table I.

\begin{tabular}{|l|l|l|r|r|r|}
\hline \multicolumn{7}{|l|}{ TABLE I: Subject Characteristics } \\
\hline & $\mathrm{N}$ & Minimum & Maximum & Mean & Std. Deviation \\
\hline Age & 20 & 19.00 & 30.00 & 23.3500 & 3.13344 \\
\hline Height $(\mathrm{cm})$ & 20 & 153.00 & 182.60 & 166.5850 & 7.96084 \\
\hline Weight $(\mathrm{kg})$ & 20 & 50.27 & 76.36 & 60.7318 & 6.86301 \\
\hline BMl(kg/m $\left.{ }^{2}\right)$ & 20 & 18.67 & 25.56 & 21.8253 & 1.84757 \\
\hline Strength Training (days/week) & 20 & .00 & 3.00 & 1.8750 & 0.64635 \\
\hline Running (miles/week) & 20 & .00 & 75.00 & 27.6000 & 19.85182 \\
\hline Age at Menarche & 19 & 10.00 & 17.00 & 12.8947 & 1.94064 \\
\hline FoM (days) & 15 & .00 & 45.00 & 27.7667 & 10.43837 \\
\hline
\end{tabular}

\section{HEALTH BELIEFS AND ATTITUDES}

Participants were asked about performance and health beliefs with regard to regular menstrual patterns (RMP) and eating habits. Nineteen responses were obtained to the question "do you feel that getting regular periods impacts performance?" (Table II). Of these, six individuals (31.6\%) indicated a belief that RMP was associated with a positive impact on performance, four individuals (21.1\%) indicated a negative impact and nine individuals (47.4\%) indicated no impact. When asked about RMP in relation to overall 
health, twelve (60\%) responded that RMP positively impacts health, seven (35\%) indicated no impact, and only one (5\%) indicated a negative impact (Table III). It is interesting to note that although well over half of those surveyed associated RMP with good health, $68.5 \%$ of respondents believed RMP had either no impact on or was a detriment to performance. This seems to suggest an interesting paradox where active women associate RMP with optimal health but not with optimal athletic performance.

Using a 5-point Likert scale, participants were asked to indicate the importance of various factors as they relate to performance $(1-2=$ low importance; $3=$ moderate importance; 4-5 = high importance). Factors listed included low body weight, low body fat, muscle mass, weight loss, weight gain, weight maintenance, low calorie diet, high protein diet and low fat intake. One-hundred percent indicated low body fat as being of moderate (35\%) or high (65\%) importance. Weight maintenance was the only other factor that was chosen by all as being of moderate $(20 \%)$ or high $(80 \%)$ importance. There was a positive correlation between the perceived import of low body weight for athletic performance and history of eating disorder diagnosis $(\mathrm{r}=0.462 ; P=0.04)$. Eleven participants (55\%) responded that a low calorie diet was of low importance to athletic performance, eight (40\%) indicated moderate importance and one (5\%) felt it was of high importance. The perceived importance of a low calorie diet decreased with age $(\mathrm{r}=$ $-0.644 ; P=0.002)$. Younger women may be more likely to engage in restrictive behaviors, although it should be noted that the importance assigned to low calorie diets was relatively low overall (95\% responded low to moderate). Given this response, it would seem that active women believe they are consuming adequate amounts despite 
spending the majority of their day in an energy deficit $>400$ kcal. Future investigations might consider evaluating perceived hunger and utilization of a measured basal metabolic rate value to clarify this discrepancy.

\begin{tabular}{|c|c|c|c|c|c|}
\hline & & Frequency & Percent & Valid Percent & Cumulative Percent \\
\hline \multirow[t]{4}{*}{ Valid } & Positive Impact & 6 & 30.0 & 31.6 & 31.6 \\
\hline & Negative Impact & 4 & 20.0 & 21.1 & 52.6 \\
\hline & No Impact & 9 & 45.0 & 47.4 & 100.0 \\
\hline & Total & 19 & 95.0 & 100.0 & \\
\hline Missing Data & & 1 & 5.0 & & \\
\hline \multicolumn{2}{|l|}{ Total } & 20 & 100.0 & & \\
\hline
\end{tabular}

TABLE III: Perceived Impact of Regular Menstrual Patterns on Overall Health

\begin{tabular}{|l|l|r|r|r|r|}
\hline & Frequency & Percent & Valid Percent & Cumulative Percent \\
\hline \multirow{4}{*}{ Valid } & 12 & 60.0 & 60.0 & 60.0 \\
\cline { 2 - 6 } & Positive Impact & 1 & 5.0 & 5.0 & 65.0 \\
\cline { 2 - 6 } & Negative Impact & 7 & 35.0 & 35.0 & 100.0 \\
\cline { 2 - 6 } & No Impact & 20 & 100.0 & 100.0 & \\
\cline { 2 - 6 } & Total & & &
\end{tabular}

\section{ENERGY BALANCE}

Over a 24-hour period, the mean energy intake for all subjects was found to be 2,094 kcal $( \pm 668)$. This is markedly less than the average predicted energy expenditure of 2,598 
$\mathrm{kcal}( \pm 400)$, resulting in the sample as a whole averaging a caloric deficit of $-504 \mathrm{kcal}$

over 24 hours. In general, participants tended to spend more hours in energy deficit $>$ $400 \mathrm{kcal}$ than in an energy surplus $>400 \mathrm{kcal}(15.2 \mathrm{hrs} \pm 9.8$ versus $1.7 \mathrm{hrs} \pm 5.4)$.

Similarly, hours spent in a catabolic state (energy balance less than zero) were more frequently observed than hours spent in an anabolic state $(20.5 \mathrm{hrs} \pm 6.8$ versus $3.5 \mathrm{hrs} \pm$ 6.8). The largest recorded energy deficit for each subject averaged $-1034 \mathrm{kcal}( \pm 779)$.

Only two participants were in perfect energy balance (within $\pm 400 \mathrm{kcal}$ of zero) for the full twenty-four hours. Neither participant reported a previous diagnosis of amenorrhea, although one had a history of LoM $>3$ months. Detailed dietary intake and energy balance data is listed under Table IV.

\begin{tabular}{|c|c|c|c|c|c|}
\hline \multicolumn{6}{|c|}{ TABLE IV: Dietary Intake and Energy Balance } \\
\hline & $\mathrm{N}$ & Minimum & Maximum & Mean & Std. Deviation \\
\hline Ending Energy Balance & 20 & -2645.00 & 2026.00 & -703.8000 & 1072.79927 \\
\hline Kcals In & 20 & 1118.00 & 3612.00 & 2093.5000 & 667.63727 \\
\hline Kcals Out & 20 & 2016.00 & 3461.00 & 2597.5500 & 400.04769 \\
\hline Protein Intake (\%) & 20 & 11.89 & 26.46 & 17.3995 & 4.01117 \\
\hline Fat Intake (\%) & 20 & 13.70 & 38.91 & 27.4240 & 6.86546 \\
\hline Carbohydrate Intake (\%) & 20 & 44.28 & 73.36 & 55.2135 & 6.66937 \\
\hline Protein Intake $(\mathrm{g})$ & 20 & 53.75 & 162.84 & 91.4235 & 31.43147 \\
\hline Fat Intake (g) & 20 & 24.68 & 117.49 & 64.3370 & 22.97003 \\
\hline Carbohydrate Intake (g) & 20 & 156.57 & 638.44 & 299.5645 & 119.63081 \\
\hline Iron Intake (mg) & 20 & 11.44 & 50.97 & 21.8295 & 10.77951 \\
\hline Energy Deficit >400 (hrs) & 20 & .00 & 24.00 & 15.1500 & 9.77254 \\
\hline Energy Surplus $>400$ (hrs) & 20 & .00 & 23.00 & 1.6500 & 5.41222 \\
\hline Hours Catabolic & 20 & .00 & 24.00 & 20.5500 & 6.84009 \\
\hline Hours Anabolic & 20 & .00 & 24.00 & 3.4500 & 6.84009 \\
\hline Largest Surplus & 20 & .00 & 2292.00 & 187.6000 & 553.33614 \\
\hline Largest Deficit & 20 & -2644.00 & .00 & -1033.8500 & 778.92870 \\
\hline
\end{tabular}




\section{ENERGY AND NUTRIENT INTAKE AND MENSTRUATION}

An independent samples $t$-test showed no difference in history of LoM $>3$ months between oral contraceptive users and non-users. A Mann-Whitney U test showed that FoM was lower among OC users compared to non-users. Spearman's rho correlational tests were conducted to assess for correlations between LoM $>3$ months, FoM, diagnosis of amenorrhea, ending energy balance, energy deficit $>400 \mathrm{kcal}$, energy surplus $>400$ kcal, hours catabolic, hours anabolic, largest energy deficit, and largest energy surplus.

Analysis of the sample data revealed a statistically significant inverse relationship between $\mathrm{LoM}>3$ months and hours spent in an energy surplus of more than $400 \mathrm{kcal}(\mathrm{r}=$ $-0.463 ; P=0.04)$. Loss of menses for greater than three months was also inversely correlated with number of meals consumed per day $(\mathrm{r}=-.491 ; P=.028)$, total kcal consumed $(\mathrm{r}=-.514 ; P=.02)$, largest energy surplus $(\mathrm{r}=-.463 ; P=.04)$, and grams of protein consumed $(\mathrm{r}=-.462 ; P=.04)$. There was no relationship between ending energy balance and LoM $>3$ months.

The impact of number of miles run per week and menstrual dysfunction, based on a quartile stratification of miles run, were analyzed using a non-parametric post hoc ANOVA with Tamhane. Significant differences were found between the upper two quartiles of distance run per week and LoM $>3$ months $(P=0.048)$.

Three participants reported past diagnosis of an eating disorder. An independent samples $t$-test revealed that these individuals were active more days per week ( 7 versus 6.2 days; 
$P=.008)$ and consumed less protein as a percentage of total calories $(P=.001)$ compared with those without a history of disordered eating. 


\section{CHAPTER V DISCUSSION AND CONCLUSIONS}

\section{PREVALENCE OF LOSS OF MENSES AND LOW ENERGY INTAKE}

Forty-five percent of the active women in this study indicated they had experienced loss of menses for greater than three months. Although the present study did not contain a sedentary control group, this is much higher than 2 to $5 \%$ rate of irregular menstruation observed in the general population (Warren \& Chua, 2008; De Souza et al., 2010). Additionally, mean menarcheal age for the study population was 12.89 years which is several months older than the present 12.43 years for the general U.S. population (Chumlea et al., 2003). Late onset of menses (occurrence of menarche beyond age fifteen) was reported by two subjects. A large majority of subjects $(68.5 \%)$ responded that regular menses had either no impact on, or were detrimental to, performance. It is possible that many athletes are indifferent to LoM or view LoM as conducive to good performance. This is dangerously flawed judgment when one considers the necessity of steroidal sex hormones to bone health. 
The participants in this study averaged a daily caloric deficit of $-504 \mathrm{kcal}$ which is in agreement with the findings of other researchers (Hassapidou \& Manstrantoni, 2001; Leblanc et al., 2002; Beals \& Hill, 2006; Tomten \& Hostmark, 2006; Ziegler, 2006). Participants averaged more hours in a catabolic state $(20.5 \mathrm{hrs})$ than in an anabolic state (3.5 hrs) and spent approximately $15 \mathrm{hrs}$ per day in a deficit greater than $400 \mathrm{kcal}$. Energy balance patterning of this sort is not conductive to lean mass development. Athletes with a previous eating disorder diagnosis may be at greatest risk for lean mass catabolism as this study revealed that protein tended to account for a smaller proportion of consumed calories in these individuals. Correction of these trends carries with it the potential to enhance athletic performance.

Oligomenorrhea and amenorrhea have serious consequences that, when unresolved, increase an athlete's risk of injury and have a lasting, negative impact on bone health (Gambacciani et al., 2004). In some instances, the use of hormonal medication to induce or regulate menses is warranted as it has been shown to have favorable, albeit short-term effects on bone metabolism (Rickenlund et al., 2010). Menstrual irregularity is not a disease in of and of itself but rather a symptom of an underlying problem. Successful and healthful resumption of menses requires identification and treatment of root cause with all other interventions regarded as temporary. The health of the athlete must always be considered of utmost importance, and any indication of poor health should be viewed as a hindrance to the pursuit of optimal performance.

Based on the results of this study, and the body literature reviewed, any efforts made to shift an amenorrheic or oligomenorrheic athlete in the direction of positive energy 
balance would likely have positive implications. This is true even for athletes who meet their 24-hour energy balance needs but spend the majority of the day in a catabolic state, as it is hours in large energy surplus that are most strongly correlated with normal menses. For coaches and athletes alike, the recognition of food as necessary fuel source and extremely valuable 'training tool' can only serve to improve performance and health.

\section{FUTURE INVESTIGATIONS}

This study stands as a preliminary investigation into the relationship between energy balance and menstrual cycle disturbance in active women. Given that significant data were found within such a small sample size, the prospect of further investigation is exciting. Menstrual and energy balance relationships may be more or less pronounced in individuals of varying sport, athletic ability, and age. If the results of this study hold true for the adolescent population, the implications for osteoporosis and stress fracture prevention and elite athlete development would be far reaching.

Subject recruitment during this study was difficult and subject response was slow and gradual. Future investigations should strive to increase participation and response rate. The number of study participants could be increased if recruitment took place at local gyms and health classes. In this study, only one interested participant was recruited from e-mailed requests for subjects. Response rate may be improved if the subject-investigator relationship begins in person. Recruiting participants through local health and fitness classes may also help to bolster the legitimacy of the study as opposed to an e-mailed 
request form an unknown investigator. Additionally, establishing a specific time line of participation upon initial contact with the subject could potentially improve the speed and rate of study completion.

Home remedies for the reestablishment of menstrual function were not examined in this investigation but a basic Internet search reveals that abortifacient herbs are touted as having the potential for inducing menstruation in amenorrheic women. Future studies may wish to evaluate the prevalence of use of these herbal remedies, which include sage, black cohosh, false unicorn root, lemon balm, sweet marjoram, pennyroyal and tansy, all of which claim to induce menstruation (August 2010, keywords "home remedies amenorrhea"). Dong quai (angelica sinensis) is used in traditional Chinese medicine to treat menstrual disorders and relieve menopausal symptoms however the efficiacy and safety of such remedies are questionable at best (Yeung \& Gubili, 2009).

Body composition was not analyzed in this study but has previously been shown to be related to within-day energy balance (Duetz et al., 2000). It is possible that body composition analysis in this sample of active females would have revealed similar association and provided further insight into the nature of the relationship between menstrual cycling and exercise.

\section{CONCLUSIONS}

Reproductive irregularity has been shown to occur frequently in athletes who end each day in energy deficit (Manore, 2007; Beals \& Hill, 2006; Nattiv et al., 2007). Although 
the women in this study exhibited a mean caloric deficit of $504 \mathrm{kcal}$, end-of-day energy balance was not related to loss of menses for greater than three months. When energy balance data were analyzed in an hourly fashion, there was a significant inverse relationship between the number of hours spent in an energy surplus $>400 \mathrm{kcal}$ and the cessation of menses for more than three months. Researchers and healthcare professionals may benefit from the examination of energy balance in an hour-by-hour manner as it may help in identifying root cause of menstrual irregularity. This would in turn allow for the development of targeted intervention strategies, potentially improving health and athletic outcomes for active women.

This study had several limitations. It is possible that the study participants failed to report all instances of energy intake or improperly estimated portion size. Since underreporting of energy intake is a known limitation of all methods of dietary record taking, the findings of this study should be comparable in accuracy to other studies relying on similar diet recall instruments. The NutriTiming ${ }^{\mathrm{TM}}$ software is available as an application for Apple's iPhone. Future use of this could decrease instances of underreporting by allowing study subjects to input energy balance information in real time. Additionally, the survey used in this study had not been previously validated and was used for the first time in this population. Care was taken to ensure that the questions asked were clear, and clarification was provided to participants when requested.

棌深 


\section{REFERENCES}

American Academy of Pediatrics, Committee on Adolescence, American College of Obstetrics and Gynecologists, Committee on Adolescent Health Care. (2006). Menstruation in girls and adolescents: Using the menstrual cycle as a vital sign. Pediatrics, 118, 2245-2250.

American Dietetic Association, Dietitians of Canada, American College of Sports Medicine. (2009). Position of the American Dietetic Association, Dietitians of Canada, and the American College of Sports Medicine: Nutrition and athletic performance. Journal of the American Dietetic Association, 109, 509-527.

Anderson, S., Dallal, G., Must, A. (2003). Relative weight and race influence average age at menarche: Results from two nationally representative surveys of US girls studied 25 years apart. Pediatrics, 111, 844-850.

Ashley, C., Lverone Kramer, M., Bishop, P. (2000). Estrogen and substrate metabolism: a review of contradictory research. Sports Medicine, 4, 221-227.

Barr, S., Prior, J., Vigna, Y. (1994). Restrained eating and ovulatory disturbances:

possible implications for bone health. American Journal of Clinical Nutrition, 59, 92-97.

Beals, K., Hill, A. (2006). The prevalence of disordered eating, menstrual dysfunction, and low bone mineral density among U.S. collegiate athletes. International Journal of Sports Nutirition and Exercise Metabolism, 16, 1-23.

Beidleman, B., Puhl, J., De Souza, M. (1995). Energy balance in female distance runners. American Journal of Clinical Nutrition, 61, 303-311.

Bellisle, F., McDevitt, R., Prentice, A. (1997). Meal frequency and energy balance. British Journal of Nutrition, 77, 57-70.

Benardot, D. (2007). Timing of energy and fluid intake: new concepts for weight control and hydration. American College of Sports Medicine Health and Fitness Journal, 11, 13-19.

Bergendahl, M., Iranmenesh, A., Evans, W., Veldhuis, J. (2000). Short-term fasting selectively suppresses leptin pulse mass and 24-hour leptin release in healthy midluteal phase women without disturbing leptin pulse frequency or its entropy control (pattern orderliness). The Journal of Clinical Endocrinology and Metabolism, 85, 207-213. 
Bolton, J., Patel, S., Lacey, H., White, S. (2005). A prospective study of changes in bone turnover and bone density associated with regaining weight in women with anorexia nervosa. Osteoporosis International, 19, 1955-1962.

Braun, H., Koehler, K., Geyer, H., Kleinert, J., Mester, J., Schänzer, W. (2009). Dietary supplement use among elite young German athletes. International Journal of Sport Nutrition and Exercise Metabolism, 19, 97-109.

Burrows, M., Bird, S. (2000). The physiology of the highly trained female endurance runner. Sports Medicine, 30, 281-300.

Castelo-Branco, C., Reina, F., Montivero, A., Colodrón, M., Vandrell, J. (2006). Influence of high-intensity training and of dietetic and anthropometric factors on menstrual cycle disorders in ballet dancers. Gynecological Endocrinology, 22, 31-35.

Çetin, A., Gökçe-Kutsal, Y., Çeliker, R. (2001). Predictors of bone mineral density in healthy males. Rheumatology International, 21, 85-88.

Chinevere, T., McClung, J., Cheuvront, S. (2007). Trace mineral losses in sweat. Current Nutrition and Food Science, 3, 236-241.

Chrousos, G., Torpy, D., Gold, P. (1998). Interactions between the hypothalamicpituitary-adrenal axis and the female reproductive system: clinical implications. Annals of Internal Medicine, 129, 229-240.

Chumlea, W., Schubert, CC., Roche, A., Kulin, H., Lee, P., Himes, J., Sun, S. (2003). Age at menarche and racial comparisons in US girls. Pediatrics, 111, 110-113.

Coiro, V., Choidera, P., Melani, G., Manfredi, G., Jotti, G., Casti, A. (2006). Different plasma neuropeptide $\mathrm{Y}$ concentrations in women athletes with and without menstrual cyclicity. Fertility and Sterility, 85, 767-769.

Davis, S., Chavers, C., Davis, B., Costa, F. (1997). Prevention of an increase in plasma cortisol during hypoglycemia preserves subsequent counterregulatory responses. Journal of Clinical Investigation, 100, 429-438.

Dellava, J., Policastro, P., Hoffman, D. (2009). Energy metabolism and body composition in long-term recovery from anorexia nervosa. International Journal of Eating Disorders, $42,415-421$.

Dennison, E., Hindmarsh, P., Fall, C., Kellingray, S., Barker, D., Phillips, D., Cooper, C. (1999). Profiles of endogenous circulating cortisol and bone mineral density in healthy elderly men. Journal of Clinical Endocrinology and Metabolism, 84, 3058-3063.

DeRuisseau, K., Cheuvront, S., Haymes, E., Sharp, R. (2002). Sweat iron and zinc losses during prolonged exercise. International Journal of Sport Nutrition and Exercise Metabolism, 12, 428-437. 
De Souza M., Toombs J., Scheid J, O’Donnall E., West S., Williams N. (2010). High prevalence of subtle and severe menstrual disturbances in exercising women: confirmation using daily hormone measures. Human Reproduction, 25, 491-503.

Ding, J., Sheckter, C., Drinkwater, B., Soules, M., Bremner, W. (1988). High serum cortisol levels in exercise-associated amenorrhea. Annals of Internal Medicine, 108, $530-534$

Dominguez, J., Goodman, L., Sen Gupta, S., Mayer, L., Fischer Etu, S., Walsh, B., Wang, J., Pierson, R., Warren, M. (2007). Treatment of anorexia nervosa is associated with increases in bone mineral density, and recovery is a biphasic process involving both nutrition and return of menses. American Journal of Clinical Nutrition, 86, 92-99.

Deutz, R., Benardot, D., Martin, D., \& Cody, M. (2000). Relationship between energy deficits and body composition in elite female gymnasts and runners. Medicine and Science in Sports and Exercise,32, 659-668.

Dušek, T. (2001). Influence of high intensity training on menstrual cycle disorders in athletes. Croatian Medical Journal, 42, 79-82.

Edmonds, D. (2006). Congenital abnormalities of the genital tract: management or mismanagement?. Journal of Obstetrics and Gynaecology, 26, 101-103.

Ersoy, B., Balkan, C., Gunay, T., Egermen, A. (2005). Factors affecting the relation between menarcheal age of mother and daughter. Child: Care, Health and Development, 31, 303-308.

Farschi, H., Taylor, M., Macdonald, I. (2004). Decreased thermic effect of food after an irregular compared with a regular meal pattern in healthy lean women. International Journal of Obesity, 28, 653-660.

Feinman, R., Fine, R. (2004). "A calorie is a calorie" violates the second law of thermodynamics. Nutrition Journal, 3:9.

Fogteloo, A., Roelfsema, F., Frölich, M., Meinders, A. (2004). Impact of meal timing and frequency on the twenty-four-hour leptin rhythm. Hormone Research, 62, 71-78.

Franko, D., Striegel-Moore, R., Thompson, D., Affenito, S., Schreiber, G., Daniels, S., Crawford, P. The relationship between meal frequency and body mass index in black and white adolescent girls: more is less. International Journal of Obesity, 32, 23-29.

Gambacciani, M., Monteleone, P., Ciaponi, M., Sacco, A., \& Genazzani, A. (2004). Effects of oral contraceptives on bone mineral density. Treatments in Endocrinology, 3, 191-196. 
Gibson, J., Mitchell, A., Harries, M., Reeve, J. (2004). Nutritional and exercise-related determinants of bone density in elite female runners. Osteoporosis International, 15, 611-618.

Golden, N., Carlson, J. (2008). The pathophysiology of amenorrhea in the adolescent. Annals of the New York Academy of Sciences, 1135, 163-178.

Grinspoon, S., Thomas, L., Miller, K., Herzog, D., Klibanski, A. (2002). Effects of recombinant human IGF-I and oral contraceptive administration on bone density in anorexia nervosa. The Journal of Clinical Endocrinology and Metabolism, 87, 2883-2891.

Halpert, S., Warren, M. (2004). Exercise and female adolescents: effects on the reproductive and musculoskeletal systems. International Sports Medicine Journal, 5, 78-88.

Hassapidou, M., Manstrantoni, A. (2001). Dietary intakes of elite female athletes in Greece. Journal of Human Nutrition and Dietetics, 14, 391-396.

Hausenblas, H., Carron, A. (2002). Assessing eating disorder symptoms in sport groups: a critique with recommendations for future research. International Sports Journal, 6, $65-74$.

Hind, K. (2008) Recovery of bone mineral density and fertility in a formerly amenorrheic athlete. Journal of Sports Science and Medicine, 7, 415-418.

Holtkamp, K., Mika, C., Heer, M., Pak, H., Hebebrand, J., Herpertz-Dahlmann, B. (2003). Reproductive function during weight gain in anorexia nervosa: leptin represents a metabolic gate to gonadotropin secretion. Journal of Neural Transmission, 110, 427-435.

Kalantaridou, S., Makrigiannakis, A., Zoumakis, E., Chrousos, G. (2004). Stress and the female reproductive system. Journal of Reproductive Immunology, 62, 61-68.

Kishali, N., İmamoglu, O., Katkat, D., Atan, T., Akyol, P. (2006). Effects of the menstrual cycle on sports performance. International Journal of Neuroscience, 116, 1549-1563.

Köpp, W., Blum, W., von Prittwitz, S., Ziegler, A., Lübbert, H., Emons, G., Herzog, W., Herpertz, S., Deter, H-C., Remschmidt, H., Hebebrand, J. (1997). Low leptin levels predict amenorrhea in underweight and eating disordered females. Molecular Psychiatry, 2, 335-340.

Krassas, G., Pontikides, N., Kaltsas, T., Papadopoulou, P., Paunkovic, J., Paunkovic, N., Duntas, L. (1999). Disturbances of menstruation in hypothyroidism. Clinical Endocrinology, 50, 655-659. 
Labayen, I., Forga, L., Martínez, J. (1999). Nutrient oxidation and metabolic rate as affected by meals containing different proportions of carbohydrate and fat, in healthy young women. European Journal of Nutrition, 38, 158-166.

Lawson, E., Donoho, D., Miller, K., Misra, M., Meenaghan, E., Lydecker, J., Wexler, T., Herzog, D., Klibanski, A. (2009). Hypercortisolemia is associated with severity of bone loss and depression in hypothalamic amenorrhea and anorexia nervosa. Journal of Clinical Endocrinology Metabolism, 94, 4710-4716.

LeBlanc, J., Diamond, P. (1986). Effect of meal size and frequency on postprandial thermogenesis in dogs. American Physiological Society, 250, 144-147.

LeBlanc, J., Mercier, I., Nadeau, A. (1993). Components of postprandial thermogenesis in relation to meal frequency in humans. Canadian Journal of Physiology and Pharmacology, 71, 879-883.

LeBlanc, J., Le Gall, F., Grandjean, V., Verger, P. (2002). Nutritional intake of French soccer players at the Clairefontaine training center. International Journal of Sport Nutrition and Exercise Metabolism, 12, 268-280.

Lobeck, C., Steinkraus, R. (1960). Effects of fasting, adrenalectomy and cortisol on bone consumption and density. American Journal of Physiology, 199, 1077-1080.

Loucks, A., Verdun, M., Heath, E. (1998). Low energy availability, not stress of exercise, alters LH pulsatility in exercising women. Journal of Applied Physiology, 84, 37-46.

Loucks, A., Thurma, J. (2003). Luteinizing hormone pulsatility is disrupted at a threshold of energy availability in regularly menstruating women. The Journal of Clinical Endocrinology and Metabolism, 88, 297-311.

Loucks, A. (2007). Low energy availability in the marathon and other endurance sports. Sports Medicine, 37, 348-352.

Lucas, J., Luca, P., Vogl, S., Gamble, G., Evans, M., Reid, I. (2003). Effect of sub-elite competitive running on bone density, body composition and sexual maturity of adolescent females. Osteoporosis International, 14, 848-856.

Lynn, B., McCord, J., Halliwill. J. (2007). Effects of the menstrual cycle and sex on postexercise hemodynamics. American Journal of Physiol Regul Intergr Comp Physiol, $292,1260-1270$.

Majdič, G. (2009). Integrative role of the brain and hypothalamus in the control of energy balance. Acta Chimica Slov, 56, 289-296.

Manore, M., Kam, L., Loucks, A. (2007). The female athlete triad: Components, nutrition issues, and health consequences. Journal of Sports Science, 25, 61-71. 
Manore, M. (2004). Nutritional recommendations and athletic menstrual dysfunction. International Sports Medicine Journal, 5, 45-55.

Maughan, R. (1999). Role of micronutrients in sport and physical activity. British Medical Bulletin, 55, 683-690.

Miller, K. (2003). Mechanisms by which nutritional disorders cause reduced bone mass in adults. Journal of Women's Health, 12, 145-150.

Misra, M., Miller, K., Almazan, C., Ramaswamy, K., Lapcharoensap, W., Worley, M., Neubauer, G., Herzog, D., Klibanski, A. (2004). Alterations in cortisol secretory dynamics in adolescent girls with anorexia nervosa and effects on bone metabolism. The Journal of Endocrinology and Metabolism, 89, 4972-4980.

Montain, S., Cheuvront, S., Lukaski, H. (2007). Sweat mineral-element responses during $7 \mathrm{~h}$ of exercise-heat stress. International Journal of Sport Nutrition and Exercise Metabolism, 17, 574-582.

Morimatsu, Y., Matsubara, S., Watanabe, T., Hashimoto, Y., Matsui, T., Asada, K., Suzuki, M. (2009). Future recovery of the normal menstrual cycle in adolescent patients with secondary amenorrhea. Journal of Obstetrics and Gynacology, 35, 545-550.

Nappi, C., Di Spiezio Sardo, A., Acunzo, G., Bifulco, G., Tommaselli, G., Guida, M., Di Carlo, C. (2003). Effects of a low-dose and ultra-low-dose combined oral contraceptive use on bone turnover and bone mineral density in young fertile women: a prospective controlled randomized study. Contraception, 67, 355-359.

Nattiv, A., Loucks, A., Manore, M., Sanborn, S., Sundgot-Borgen, J., \& Waaren, M. (2007). Position of the American College of Sports Medicine: The female athlete triad. Medicine and Science in Sports, 39, 1867- 1881.

Perkins, R., Hall, J., Martin, K. (2001). Aetiology, previous menstrual function and patterns of neuro-endocrine disturbance as prognostic indicators in hypothalamic amenorrhoea. Human Reproduction, 16, 2198-2205.

Platte, P., Pirke, K., Trimborn, P., Pietsch, K., Krieg, J., Fichter, M. (1994). Resting metabolic rate and total energy expenditure in acute and weight recovered patients with anorexia nervosa and in healthy young women. International Journal of Eating Disorders, 16, 45-52.

Prior, J., Kirkland, S., Joseph, L., Kreiger, N., Murray, T., Hanley, D., Adachi, J., Vigna, Y., Berger, C., Blondeau, L., Jackson, S., Tenenhouse, A. (2001). Oral contraceptive use and bone mineral density in premenopausal women: cross-sectional, population-based data from the Canadian Multicentre Osteoporosis Study. Canadian Medical Association Journal, 165, 1023-1029. 
Rao, G., Arslanian, S. (2009). Office evaluation and management of the obese adolescent with metabolic syndrome. Obesity and Weight Management, 5, 229-236.

Real, F., Svanes, C., Macsali, F., Omenaas, E. (2008). Hormonal factors and respiratory health in women - a review. The Clinical Respiratory Journal, 2, 111-119.

Redman, L., Loucks, A. (2005). Menstrual Disorders in Athletes. Sports Medicine, 35, 747-755.

Reed, S., Scholes, D., LaCroix, A., Ichikawa, L., Barlow, W., Ott, S. (2003). Longitudinal changes in bone density in relation to oral contraceptive use. Contraception, 68, 177-182.

Rickenlund, A., Thorén, M., Nybacka Å., Frystyk, J., Hirschberg, A. Lindén. (2010). Effects of oral contraceptives on diurnal profiles of insulin, insulin-like growth factor binding protein-1, growth hormone and cortisol in endurance athletes with menstrual disturbance. Human Reproduction, 25, 85-93.

Rosetta, L., Condé da Silva Fraga, E., Mascie-Taylor, C. (2001). Relationship between self-reported food and fluid intake and menstrual disturbance in female recreational runners. Annals of Human Biology, 28, 444-454.

Ruffing, J., Nieves, J., Zion, M., Tendy, S., Garrett, P., Lindsay, R., Cosman, F. The influence of lifestyle, menstrual function and oral contraceptive use on bone mass and size in female military cadets. Nutrition and Metabolism, 4.

Sapolsky, R., Romero, M., Munck, A. (2000). How do glucocorticoids influence stress response? Integrating permissive, suppressive, stimulatory, and preparative actions. Endocrine Reviews, 21, 51-89.

Schwartz, M., Seeley, R. (1997). Neuroendocrine responses to starvation and weight loss. New England Journal of Medicine, 336.

Sherman, R., Thompson, R. (2005). NCAA coaches survey: The role of the coach in identifying and managing athletes with disordered eating. Eating Disorders, 13, 447-466.

Shils, M., Shike, M., Ross, A., Caballero, B., Cousins, R. (2006). Modern Nutrition in Health and Disease, Tenth ed. Philadelphia: Lippincott Williams \& Wilkins.

Shoepe, H., Snow, C. (2005). Oral contraceptive use in young women is associated with lower bone mineral density than that of controls. Osteoporosis International, 16, $1538-1544$.

Slap, G. (2003). Menstrual disorders in adolescence. Best Practice \& Research Clinical Obstetrics and Gynaecology, 17, 75-92. 
Stafford, D. (2005). Altered hypothalamic-pituitary-ovarian axis function in young female athletes: implications and recommendations for management. Treatment Endocrinology, 4, 147-154.

Stokić, E., Srdić, B., Barak, O. (2005). Body mass index, body fat mass and the occurrence of amenorrhea in ballet dancers. Gynecological Endocrinology, 20, 195-199.

Strokosch, G., Friedman, A., Wu, S., Kamin, M. (2006). Effects of an oral contraceptive (norgestimate/ethinyl estradiol) on bone mineral density in adolescent females with anorexia nervosa: A double-blind, placebo controlled study. Journal of Adolescent Health, 39, 819-827.

Symons, T., Sheffield-Moore, M., Wolfe, R., Paddon-Jones, D. (2009). A moderate serving of high-quality protein maximally stimulates protein synthesis in young and elderly subjects. Journal of the American Dietetic Association, 109, 1582-1586.

Tabata, I., Ogita, F., Miyatchi, M., Shibayama, H. (1991). Effect of low blood glucose on plasma CFR, ACTH, and cortisol during prolonged physical exercise. Journal of Applied Physiology, 71, 1807-1812.

Tai, M., Castillo, P., Pi-Sunyer, F. (1991). Meal size and frequency: effect on the thermic effect of food. American Journal of Clinical Nutrition, 54, 783-787.

The Practice Committee of the American Society for Reproductive Medicine. (2008). Current evaluation of amenorrhea. Fertility and Sterility, 90, 219-225.

Tomten, S., Hostmark, A. (2006). Energy balance in weight stable athletes with and without menstrual disorders. Scandinavian Journal of Medicine and Science in Sports, $16,127-133$.

Torstveit, M., Sundgot-Borgen, J. (2005). Participation in leanness sports but not training volume is associated with menstrual dysfunction: a national survey of 1276 elite athletes and controls. British Journal of Sports Medicine, 39, 141-147.

Trutschnigg, B., Chong, C., Habermayerova, L., Karelis, A., Komorowski, J. (2008). Female boxers have high bone mineral density despite low body fat mass, high energy expenditure, and a high incidence of oligomenorrhea. Applied Physiology in Nutrition and Metabolism, 33, 863-869.

Warren, M., Brooks-Gunn, J., Fox, R., Holderness, C., Hyle, E., Hamilton, W., Hamilton, L. (2003). Persistent Osteopenia in ballet dancers with amenorrhea and delayed menarche despite hormone therapy: a longitudinal study. Fertility and Sterility, 80, 398-404.

Warren, M., Chua, A. (2008). Exercise-induced amenorrhea and bone health in the adolescent athlete. Annals of the New York Academy of Sciences, 1135, 244-252. 
Warren, M., Miller, K., Olson, W., Grinspoon, S., Friedman, A. (2005). Effects of an oral contraceptive (norgestimate/ethinyl estradiol) on bone mineral density in women with hypothalamic amenorrhea and Osteopenia: an open-label extension of a double-blind, placebo-controlled study. Contraception, 72, 206-211.

Weimann, E., Blum, W., Schwidergall, S., Böhles, H. (1999). Hypoleptinemia in female and male elite gymnasts. European Journal of Clinical Investigation, 29, 853-860.

Welt, C., Chan, J., Bullen, J., Murphy, R., Smith, P., DePaoli, A., Karalis, A., Mantzoros, C. (2004). Recombinent human leptin in women with hypothalamic amenorrhea. New England Journal of Medicine, 351, 987-997.

Wiksten-Almströmer, M., Hirschberg, L., Hagenfeldt, K. (2009). Reduced bone mineral density in adult women diagnosed with menstrual disorders during adolescence. Acta Obstetricia et Gynecologia, 88, 543-549.

Williams, N., Leidy, H., Flecker, K., Galucci, A. (2006). Food attitudes in female athletes: Association with menstrual cycle length. Journal of Sports Sciences, 24, 979-986.

Yueng, K., Gubili, J. (2009). Dong quai (angelica sinensis). Journal for the Society of Integrative Oncology, 7, 121-122.

Zacharias, L., Wurtman, R. (1969). Age at menarche: genetic and environmental influences. New England Journal of Medicine, 280, 868-875.

Zangeneh, F. (2009). Stress and female reproductive system: disruption of corticotrophinreleasing hormone/opiate balance by sympathetic nerve traffic. Journal of Family and Reproductive Health, 3, 69-76.

Zanker, C. (2006). Regulation of reproductive function in the athletic woman: an investigation of the roles of energy availability and body composition. British Journal of Sports Medicine, 40, 489-490.

Ziegler, P., Jonnalagadda, S. (2006). Nutrient intake is inadequate for US national synchronized skaters. Nutrition Research, 26, 313-317.

Ziegler, P., Khoo, C., Sherr, B., Nelson, S., Larson, W., Drewnowski, A. (1998). Body image and dieting behaviors among elite figure skaters. International Journal of Eating Disorders, 24, 421-427. 


\section{APPENDICES}

\section{APPENDIX I : Research Questionnaire}

\section{Research Questionnaire}

1. Age:

2.

3. Height:

4.

5. Weight:

6.

7. Number of days per week that you run:

8.

9. Number of miles run per week:

10.

11. Number of days per week that you weight train:

12. Have you ever had a menstrual period?

13. Yes No

If yes, please indicate your age at menarche (first period):

If no, please proceed to question \#11 
14. Please indicate how often (number of days) your menstrual cycles occur:

15. Have you ever been diagnosed by a physician as amenorrheic?

16.Yes No Don't Know

17.

18. Have you ever gone more than three months without a menstrual cycle?

19. Yes No

20.

21. Have you ever been diagnosed with an eating disorder?

22. Yes No

23. If no, please continue to question \#13

24.

25. Please indicate type of disorder:

26. [ ] Anorexia Nervosa

27.[ ] Bulimia Nervosa

28. [ ] Binge Eating Disorder

29. [ ] Eating Disorder Not Otherwise Specified

30.[ ] Don't Know

31.

32. Are you currently taking oral contraceptives?

33. Yes No

If yes, please list what kind:

34. Have you ever been prescribed hormonal medication (such as birth control pills) as a method of inducing or regulating menses (period)?

35. Yes No

36. 
37. Do you feel that getting regular periods impacts performance?

38. Yes No

39. If yes, how do you feel it impacts performance?

40.

41.

42. Do you feel that getting regular periods impacts overall health?

43. Yes No

44. If yes, how do you feel it impacts overall health?

45.

46.

47. How many meals do you typically eat in a day:

48.

49. How many snacks do you typically eat in a day:

50.

51. Check all that apply:

52.I eat the way I do because of:

53. [ ] My schedule

54. [ ] The convenience

55.[ ] I am frequently hungry

56.[ ] I am not frequently hungry

57. [ ] I believe it to be healthy

58.[ ] Other:

59.

60. Please indicate how important these factors are to your performance. 


$\begin{array}{lccccc}\text { Importance } & \text { Low Importance } & & & & \text { High } \\ \text { Low Body Weight } & 1 & 2 & 3 & 4 & 5 \\ \text { Low Body Fat } & 1 & 2 & 3 & 4 & 5 \\ \text { Muscle Mass } & 1 & 2 & 3 & 4 & 5 \\ \text { Weight Loss } & 1 & 2 & 3 & 4 & 5 \\ \text { Weight Gain } & 1 & 2 & 3 & 4 & 5 \\ \text { Weight Maintenance } & 1 & 2 & 3 & 4 & 5 \\ \text { Low Calorie Diet } & 1 & 2 & 3 & 4 & 5 \\ \text { High Protein Diet } & 1 & 2 & 3 & 4 & 5 \\ \text { Low Fat Intake } & 1 & 2 & 3 & 4 & 5\end{array}$




\section{APPENDIX II: Data Entry Form}

\section{NutriTiming ${ }^{t m}$ Data Entry Form}

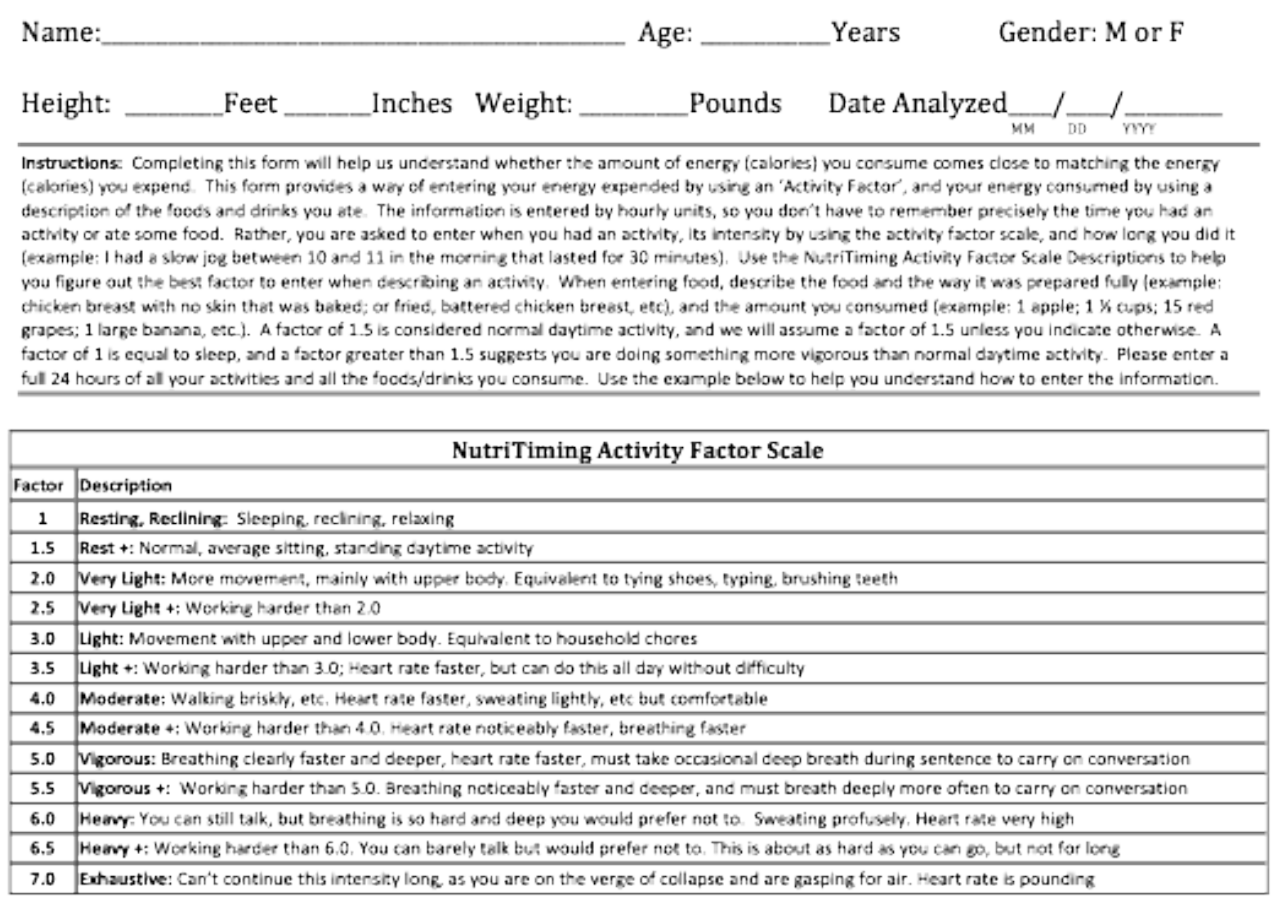

\begin{tabular}{|c|c|c|c|c|c|}
\hline $\begin{array}{l}\text { Begin } \\
\text { Hour }\end{array}$ & $\begin{array}{l}\text { End } \\
\text { Hour }\end{array}$ & $\begin{array}{l}\text { Activity } \\
\text { Factor }\end{array}$ & $\begin{array}{l}\text { Activity } \\
\text { Description }\end{array}$ & Food/Drink Description & $\begin{array}{l}\text { Food/Drink } \\
\text { Amount }\end{array}$ \\
\hline \multicolumn{6}{|c|}{$* * * *$ Begin Example**** } \\
\hline $12 \mathrm{am}$ & $7 \mathrm{am}$ & 1.0 & Sleep & & \\
\hline \multirow[t]{6}{*}{$7 \mathrm{am}$} & $89 \mathrm{~m}$ & 1.5 & Nothing Special & Whole Wheat Waffles (Froven-Kellogg) & 3 \\
\hline & & & & Maple Syrup & 2 Tablespcons \\
\hline & & & & $1 \%$ Milk & 1 Cup \\
\hline & & & & Orange Juice (from cancentrate) & 1.5 cups \\
\hline & & & & Cotfee & 2 Cups \\
\hline & & & & $1 \%$ Milk for Coffee & 2 Tablespcons \\
\hline $10 \mathrm{am}$ & $11 \mathrm{am}$ & 5.0 & Jog 30 minutes & Gatarade & 16 Ounces \\
\hline \multirow{5}{*}{ 12noan } & $1 \mathrm{pm}$ & 1.5 & Nothing Special & Medium size beef sandwich with white & 1 Sandwizh \\
\hline & & & & bread, mayonnaise, lettuce, and tomato. & \\
\hline & & & & Cotfee & 2 Cups \\
\hline & & & & Actificial Colfee Creamer & 2 Packets \\
\hline & & & & Agple Pie & 1 SEse (small) \\
\hline $5 \mathrm{pm}$ & $6 \mathrm{gm}$ & 4.0 & Walk 1 hour & Water & 16 ounces \\
\hline \multirow[t]{4}{*}{$7 \mathrm{pm}$} & $8 \mathrm{gm}$ & 1.5 & Nothing Special & Lasagna with ground beef and cheese & Large Plate \\
\hline & & & & Lettuce Salad with Tomatoes and Cucumbers & Medium Size Solad \\
\hline & & & & Blue Cheese Salad Dressing & 1 Tablespeon \\
\hline & & & & Fed Wine & 1 Medium Glass \\
\hline $10 \mathrm{pm}$ & $119 \mathrm{pm}$ & 1.5 & Nothing Speoal & Popcorn (air popped; no butter) & 100 Calorie Pack \\
\hline \multicolumn{6}{|c|}{$* * *$ End Example $* * *$} \\
\hline
\end{tabular}

Page 


\begin{tabular}{|c|c|c|c|c|c|}
\hline $\begin{array}{l}\text { Begin } \\
\text { Hour }\end{array}$ & $\begin{array}{l}\text { End } \\
\text { Hour }\end{array}$ & $\begin{array}{l}\text { Activity } \\
\text { Factor }\end{array}$ & $\begin{array}{l}\text { Activity } \\
\text { Description }\end{array}$ & Food/Drink Description & $\begin{array}{l}\text { Food/Drink } \\
\text { Amount }\end{array}$ \\
\hline & & & & & \\
\hline & & & & & \\
\hline & & & & & \\
\hline & & & & & \\
\hline & & & & & \\
\hline & & & & & \\
\hline & & & & & \\
\hline & & & & & \\
\hline & & & & & \\
\hline & & & & & \\
\hline & & & & & \\
\hline & & & & & \\
\hline & & & & & \\
\hline & & & & & \\
\hline & & & & & \\
\hline & & & & & \\
\hline & & & & & \\
\hline & & & & & \\
\hline & & & & & \\
\hline & & & & & \\
\hline & & & & & \\
\hline & & & & & \\
\hline & & & & & \\
\hline & & & & & \\
\hline & & & & & \\
\hline & & & & & \\
\hline & & & & & \\
\hline & & & & & \\
\hline & & & & & \\
\hline & & & & & \\
\hline & & & & & \\
\hline & & & & & \\
\hline & & & & & \\
\hline & & & & & \\
\hline & & & & & \\
\hline & & & & & \\
\hline & & & & & \\
\hline & & & & & \\
\hline & & & & & \\
\hline & & & & & \\
\hline & & & & & \\
\hline & & & & & \\
\hline & & & & & \\
\hline & & & & & \\
\hline & & & & & \\
\hline & & & & & \\
\hline & & & & & \\
\hline & & & & & \\
\hline & & & & & \\
\hline & & & & & \\
\hline
\end{tabular}




\section{APPENDIX III: NutriTiming ${ }^{т м}$ Example}

nutritiming

energy balance experts

Client: ATsubject17

Weight: 137.0 pounds

Average of 3 Days

Age: 22 yrs.

Gender: Female

Energy Balance

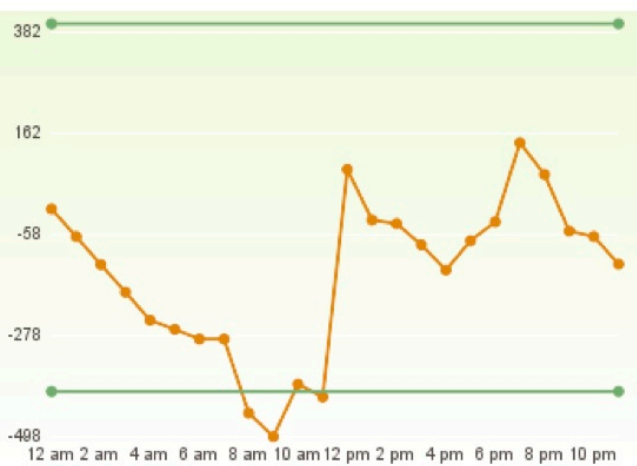

Nutrients

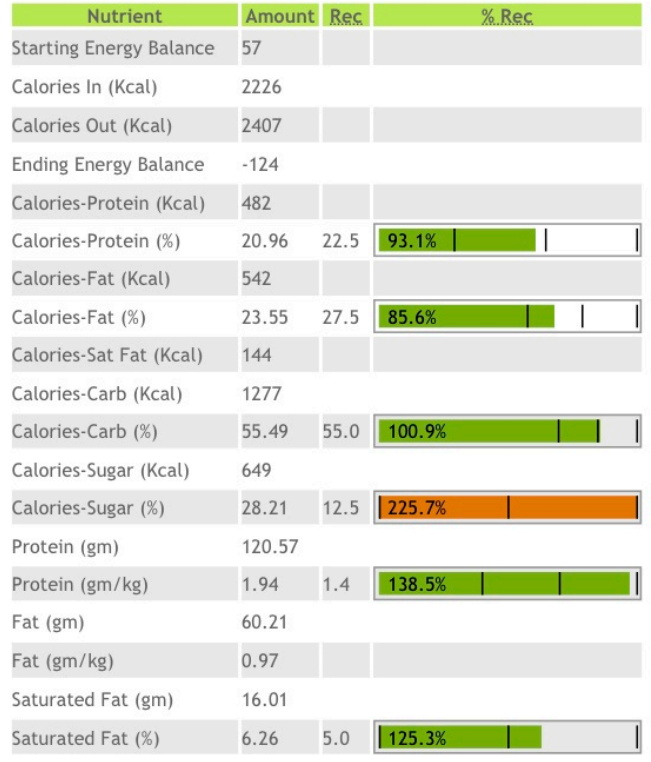

Monounsaturated Fat (gm) 16.19

Monounsaturated Fat (\%) 6.33

Polyunsaturated Fat (gm) 8.33

\begin{tabular}{l|l|}
17.5 & $36.2 \%$ \\
\hline
\end{tabular}

\begin{tabular}{|c|c|c|c|}
\hline Nutrient & Amount & Rec. & \%.ReG \\
\hline Beta Carotene (Âिg) & 8329.39 & & \\
\hline Vitamin D (IU) & 157.69 & 200.0 & $78.8 \%$ \\
\hline Vitamin E (mg) & 16.94 & 15.0 & $113.0 \%$ \\
\hline Vitamin K (ÂAg) & 200.08 & 90.0 & $222.3 \%$ \\
\hline Vitamin B1 (mg) & 3.03 & 1.1 & $275.3 \%$ \\
\hline Vitamin B2 (mg) & 3.80 & 1.1 & $345.1 \%$ \\
\hline Vitamin B3 (mg) & 53.09 & 14.0 & $379.2 \%$ \\
\hline Vitamin B6 (mg) & 5.63 & 1.3 & $432.7 \%$ \\
\hline Vitamin B12 (Âpg) & 11.30 & 2.4 & $470.8 \%$ \\
\hline Vitamin C (mg) & 170.85 & 75.0 & $227.8 \%$ \\
\hline Choline Total (mg) & 329.54 & 425.0 & $77.5 \%$ \\
\hline Folic Acid (Â $\mu \mathrm{g})$ & 437.01 & & \\
\hline Folate (DFE) & 1008.84 & 400.0 & $252.2 \%$ \\
\hline Folate Total (Â $\mu \mathrm{g})$ & 705.00 & & \\
\hline Folate Food (Â $\mu g)$ & 268.00 & & \\
\hline Pantothenic Acid (mg) & 11.97 & 5.0 & $239.3 \%$ \\
\hline Calcium (mg) & 1240.04 & 1000.0 & $124.0 \%$ \\
\hline Copper (Âug) & 1.92 & 900.0 & $0.2 \%$ \\
\hline Iron (mg) & 35.01 & 18.0 & $194.5 \%$ \\
\hline Magnesium (mg) & 491.37 & 310.0 & $158.5 \%$ \\
\hline Manganese (mg) & 4.96 & 1.8 & $275.8 \%$ \\
\hline Phosphorus (mg) & 1891.68 & 700.0 & $270.2 \%$ \\
\hline
\end{tabular}

